\title{
La actividad bacaladera bajo el franquismo (1939-1975) *
}

\author{
- María del Carmen Espido Bello \\ Universidade de Santiago de Compostela \\ - JESÚs GiRÁLDEZ RiVERO \\ Universidade de Santiago de Compostela
}

\section{Introducción}

Secularmente España fue el principal mercado de bacalao del Atlántico salado y seco; un alimento barato, fácilmente transportable y de prolongada conservación, lo que permitía demorar su consumo. ${ }^{1} \mathrm{Su}$ relevancia se mantuvo en la época contemporánea; desde mediados del siglo XIX ocupó un lugar muy destacado en el total de importaciones, proporcionando sustanciosos ingresos a la Hacienda pública. En ausencia de producción propia, el elevado volumen de compras se reflejó en el ámbito internacional; hasta la Guerra Civil, España fue el primer importador y el mayor mercado mundial de bacalao.

El franquismo, con su política autárquica, restringió las llegadas del extranjero al tiempo que impulsó la actividad; España se convirtió en una importante potencia bacaladera. Nuestro objetivo es analizar este «ciclo español del bacalao», una etapa que se inicia tras la Guerra Civil y finaliza en los años setenta, con la ampliación por Canadá de su Zona Económica Exclusiva a 200 millas marítimas.

Este artículo busca incidir en tres cuestiones claves. En primer lugar, en el papel desempeñado por el Estado en el arranque y expansión de la actividad bacaladera, con importantes estímulos a la construcción de una flota de gran-

\footnotetext{
* Agradecemos a los evaluadores anónimos, cuya atenta lectura y sugerencias han contribuido a mejorar la versión final de este texto. Este trabajo ha contado con la financiación del proyecto «Salarios, actividad y niveles de vida en Galicia 1850-1950», Ministerio de Economía y Competitividad (HAR2013-47277-C2-2-p) y también del proyecto «Pesca, conserva y congelado: frontera, organización, instituciones y tecnología en la historia reciente de la pesca española», Ministerio de Economía y Competitividad (HAR2017-88128-R).

1. López Losa (2001).
} 
des unidades y de amplio radio de acción, por la necesidad de acceder a caladeros situados en las alejadas costas del Atlántico noroccidental. En segundo lugar, en el carácter industrial de la actividad; el procesado de bacalao, intensamente subsidiado por el Estado, acabó convirtiendo a España en el mayor productor internacional de bacalao salado y seco, por delante de países tradicionalmente productores. Al mismo tiempo, se configuraba con un claro carácter monopolístico, concentrándose flota y transformación en apenas dos empresas de grandes dimensiones, que hasta su desaparición se mantuvieron a la cabeza del sector pesquero y entre las mayores sociedades no financieras en las provincias donde radicaban. En tercer lugar, en el resultado de este proceso en términos de la balanza comercial española de bacalao; primero, una exitosa sustitución de importaciones, que contribuyó al abastecimiento de alimentos para el mercado interno, y, después, un fuerte crecimiento de las exportaciones. España se convirtió en uno de los principales países productores y exportadores de bacalao.

Para responder a las cuestiones señaladas el artículo se divide en cuatro apartados. En los dos iniciales se analiza el papel del Estado y los factores que incidieron en la evolución de la flota y de las capturas. Esta división responde a razones expositivas, pues el primero se centra en la etapa que va desde finales de la Guerra Civil hasta los años cincuenta, cuando tuvo lugar el arranque de la actividad, con la aparición de grandes empresas beneficiadas por el Estado, la constitución de una flota y el despegue de la producción, mientras el segundo atiende a la evolución durante los años sesenta y setenta, una etapa de madurez, de aparición de nuevos agentes, pero también de consolidación de la producción y de cambios profundos en la composición de la flota. En el tercero se estudia la industria procesadora, con especial atención a las transformaciones de la década de los sesenta, cuando la mayor libertad de industria alentó el nacimiento de numerosas empresas procesadoras, alterando la estructura de décadas anteriores. El cuarto se dedica a la evolución del comercio exterior; primero observamos el comportamiento de las importaciones de bacalao, condicionadas por las estrictas restricciones cuantitativas y la escasez de divisas, centrándonos después en las exportaciones, principalmente en los años sesenta, cuando tras haberse completado la sustitución de importaciones la producción alimenta la demanda de exportación. En el último apartado se recogen las principales conclusiones y se efectúa una evaluación de conjunto.

\section{Los problemas del despegue: 1939-1950}

El estallido de la Guerra Civil española asestó un fuerte golpe al mercado de bacalao: las importaciones cayeron, de $57.714 \mathrm{t}$ anuales en el trienio 
1933-1935 a 30.167 en 1936-1938, ${ }^{2}$ paralizándose la producción al ocuparse en labores bélicas la flota de PYSBE, única empresa española productora de bacalao. La guerra mundial, con el cierre de las aguas del Atlántico Norte, impidió regularizar completamente la actividad hasta finales del conflicto. ${ }^{3}$

Las pautas institucionales y económicas del primer franquismo determinaron la actividad bacaladera en la década de los cuarenta. Su «nacionalización» permitía la ansiada sustitución de unas importaciones a las que tradicionalmente se acusaba de pesar como una losa sobre la balanza comercial española, con «grave detrimento de la economía nacional». ${ }^{4}$ La política regulatoria de «condicionamiento industrial» favoreció la pesca marítima, por ser abastecedora de alimentos baratos y por el interés del Estado en reactivar el sector industrial mediante el estímulo de la construcción naval, por sus efectos de arrastre sobre la producción siderúrgica, acero laminado, motores o maquinaria. ${ }^{5}$ La irrupción del Estado en el sector pesquero fue arrolladora. El Crédito Naval, inaugurado por la Ley de 2 de junio de 1939 y desarrollado por el Reglamento de 15 de marzo de 1940, asentó un mecanismo de financiación de la flota a largo plazo que impulsó su crecimiento y su transformación. Completado y modificado posteriormente, se caracterizó en conjunto por unos tipos de interés muy bajos, muy bonificados, importantes beneficios fiscales y plazos de amortización muy dilatados. También los astilleros recibieron ayudas similares para la ampliación de las instalaciones y primas a la construcción. ${ }^{6}$

La pesca del bacalao resultó especialmente beneficiada. Se delimitó una flota bacaladera de entre 35 y 40 barcos y 35.000 t de arqueo total, vinculándose la concesión de las ayudas a la de las factorías de procesado y quedando los permisos para su instalación sujetos a las exigencias genéricas para las nuevas industrias. ${ }^{7}$ La construcción de buques debía ser autorizada por la Dirección General de Pesca Marítima, con un compromiso de suministro de $1.000 \mathrm{t}$ de pescado salpresado durante un mínimo de diez años; el número de barcos debía ser dos al menos y estar iniciada su construcción. ${ }^{8}$ Los buques destinados a esta actividad disfrutarían de una prima de 480 pesetas por tonelada bruta de arqueo hasta $3.000 \mathrm{t}$ de desplazamiento, mientras que para el resto de los pesqueros la prima se situaba en 370 pesetas. Una actuación

2. Gerhardsen (1949), p. 161; Santacreu (1988).

3. Lledó (1943), pp. 26-36; Tolosa (2000).

4. Las cuantiosas importaciones de bacalao como fuente de problemas para la economía española cuenta con una larga tradición en la literatura económica, que se remonta al siglo XVIII y se prolonga hasta el estallido de la Guerra Civil (López Losa, 2000; Lledó, 1943:29).

5. Pires (2003), López Losa (2008).

6. Giráldez (2005); Alonso (1982); Ogea y Balseyro (1944).

7. Lledó (1943), p. 36.

8. BOE, $23 / 6 / 1940$. 
calificada como de «intervención total del Estado en la industria bacaladera». ${ }^{9}$ La nacionalización de la pesca de bacalao se concretó en tres empresas: PYSBE, PEBSA y COPIBA.

Pesquerías y Secaderos de Bacalao de España S.A. (PYSBE) fue la principal. Creada antes de la Guerra Civil y con sede en Pasaia, contaba con una flota de entidad, una red de almacenes en diversas ciudades españolas, delegaciones en los principales centros bacaladeros internacionales y un reconocimiento de marca, por sus campañas de publicidad y marketing, que le permitía disfrutar de una destacada cuota de mercado. Las importantes ayudas concedidas por el nuevo régimen a PYSBE le permitieron incrementar notablemente su dimensión. En 1953 su flota ascendía a 13 bous con 15.500 TRB, 13.000 CV y 670 tripulantes. ${ }^{10}$ Su factoría de procesado de Pasaia se completó con otra en Ferrol, inaugurada en 1943, que disponía de seis modernos túneles de transformación y una capacidad de secado de bacalao de $14.000 \mathrm{t}$ anuales. ${ }^{11}$ PYSBE mantuvo su actividad con muchas dificultades en los años de la guerra mundial, pero en 1946 cuando regularizó el trabajo en Terranova sus capturas ascendieron a $38.922 \mathrm{t}$ de bacalao fresco, que representaban unas 15.569 t en salazón. ${ }^{12}$

En definitiva, PYSBE obtuvo del nuevo régimen ventajas sustanciales que le permitieron aprovechar unas aguas muy fértiles tras la veda impuesta por la Segunda Guerra Mundial. Sin embargo, la entrega de su nueva flota padeció considerables retrasos por los graves problemas de suministro de productos siderúrgicos, demoras en la entrega de los motores, materiales de cubierta y múltiples trabas administrativas que afectaban a la construcción naval; en 1953 todavía seguían activos la mayoría de los vapores con los que había iniciado sus trabajos en la década de los veinte. Con todo, la importancia de esta empresa se reflejó en unas descargas de bacalao que, hasta 1953, ascendieron al 70\% del total, manteniéndose hasta su cierre como la principal empresa bacaladera española (gráfico 1).

Aprovechando las favorables perspectivas de la demanda y las dificultades existentes para la importación de bacalao germinaron otras iniciativas empresariales. En mayo de 1938 se constituyó en Salamanca la sociedad Industrias Marítimas Españolas S.A. (IMESA), que no tardó en cambiar su razón social por Pesquerías Españolas de Bacalao S.A. (PEBSA), a fin de ejercer la «pes-

9. Lledó (1943), pp. 30-33, 190.

10. Los bous empleaban una red en forma de bolsa cónica. Su apertura vertical se obtenía mediante el empleo de cables o cadenas como lastre en la relinga inferior de la boca y flotadores, de vidrio o metálicos, en la superior. La apertura horizontal se conseguía a través de dos grandes «puertas» que actuaban en el arrastre a modo de cometas, por lo que también se conoce como arte de puertas. El largado y la recogida del arte se efectuaba por el costado, por lo que también se denomina de arrastre lateral.

11. López Losa (2008); Tolosa (2000); Garay (1985).

12. Estadística de Pesca (1946). 
GRÁFICO 1 - Bacalao salado desembarcado por las «empresas bacaladeras nacionales», 1945-1953 (Tm)

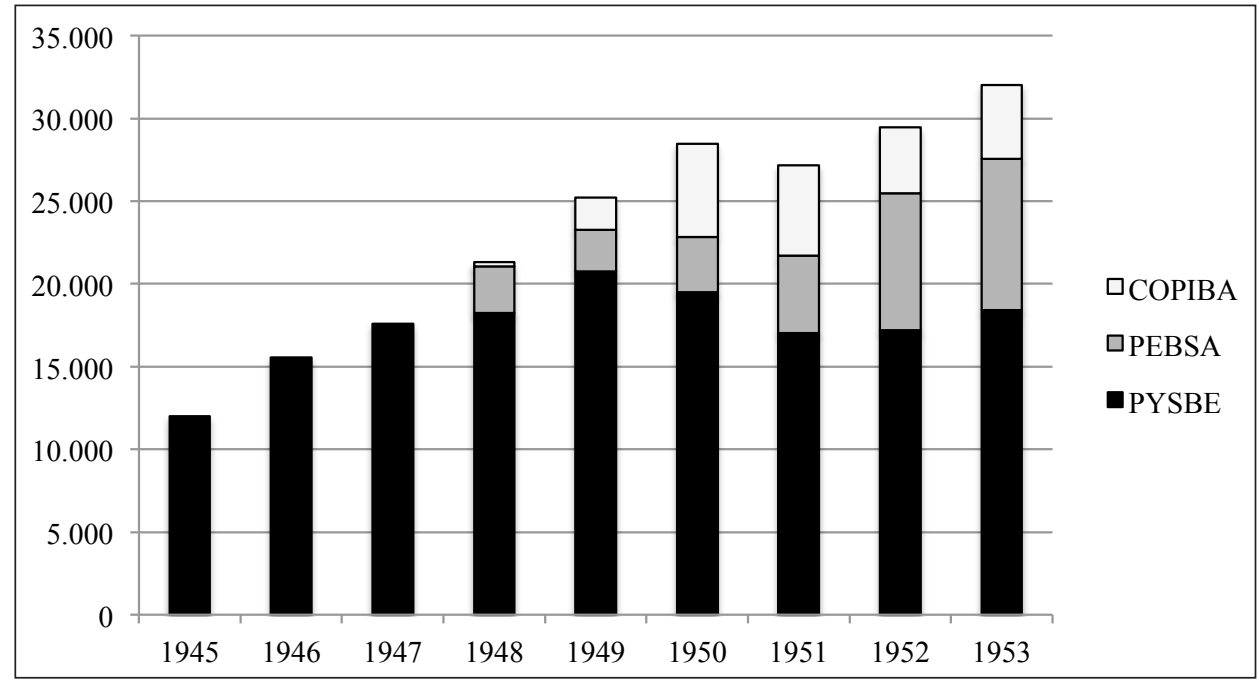

Fuente: Elaboración propia a partir de Estadística de Pesca (en adelante EP).

ca, preparación y venta del bacalao y sus derivados». ${ }^{13} \mathrm{~A}$ pesar de estar también fuertemente subsidiada por el Instituto de Crédito para la Reconstrucción Nacional, el retraso en la construcción de la flota le decidió, en 1944, a participar en ASTANO S.A. Esta participación implica una integración cuasi vertical en la que destaca, además, el peso alcanzado en su accionariado por el Banco Pastor, en estos años implicado en la creación de un importante grupo industrial; de hecho, el banco participaba en su Consejo de Administración y, desde 1948, Pedro Barrié de la Maza presidía ambas empresas. ${ }^{14}$ También trabajaban en la construcción de una factoría procesadora en el puerto de A Coruña. ${ }^{15}$ Los proyectos de PEBSA se vieron también condicionados por el conjunto de problemas que afectaban a la construcción naval: en 1953 su flota se componía de 6 barcos con 8.140 TRB, 7.900 CV y 420 tripulantes. Hasta finales de la década no pudo completar su flota ni inaugurar su factoría de A Coruña, con una capacidad de secado de $80 \mathrm{t}$ diarias de bacalao, debiendo recurrir a la planta procesadora de COPIBA en Vigo hasta $1959 .{ }^{16}$

La Compañía de Pesca e Industrias del Bacalao S.A. (COPIBA) fue la de menor dimensión de las denominadas empresas bacaladeras nacionales.

13. Escritura de constitución.

14. Carmona y Nadal (2005), p. 286.

15. PEBSA, Memorias (1942 y 1944).

16. PEBSA, Memorias de varios años; Libro de Actas, 25/5/1959. 
Constituida en febrero de 1940, los planes de la empresa comprendían la construcción de una factoría en Vigo y una flota de 10 barcos; sin embargo, los problemas de la economía española y concretamente de la construcción naval obligaron a COPIBA a limitar a 4 sus buques, con un total de 3.900 TRB, 7.200 CV y 272 tripulantes que no entrarían en actividad, al igual que su factoría, hasta los últimos años cuarenta. ${ }^{17}$ Esta escasa dimensión se compensó con la alianza empresarial con PEBSA.

Las tres empresas bacaladeras citadas compartieron algunas características. Por un lado, al ser las más beneficiadas por la Ley del crédito naval del año 1939, pudieron construir las mayores flotas de España: hasta 1961 representaron el $23 \%$ de la flota pesquera superior a 100 TRB y la totalidad de la de más de 1.000 TRB; aún en 1966 suponía casi el 60\% de la flota de las empresas que contaban con más de $5.000 \mathrm{TRB} .{ }^{18}$ Las grandes dimensiones de sus buques los dotaban de una considerable autonomía, permitiéndoles campañas de cuatro o cinco meses en Terranova, donde obtenían sus principales capturas, Labrador, Groenlandia o Nueva Escocia. Buena parte del procesado del bacalao se realizaba a bordo; los trabajos iniciales (desescamado, descabezado, eviscerado y apertura en forma de hoja) se efectuaban en cubierta y posteriormente se trasladaba a las bodegas, donde se clasificaba por tamaños y se salaba. Su capacidad de bodegas rondaba las $1.000 \mathrm{t}$ de bacalao verde, una escala mínima por debajo de la cual las condiciones económicas eran poco rentables. Una vez descargado en tierra, este bacalao verde, con alto contenido en humedad, se almacenaba en cámaras frigoríficas, siendo después lavado, pelado, secado artificialmente en túneles, mediante una corriente de aire seco, y embalado. Además, se elaboraban filetes, sin piel y sin espinas, aceite de hígado de bacalao, etc. Por otro lado, estas empresas estaban fuertemente vinculadas con la distribución, pues los principales accionistas procedían del comercio de bacalao: en PEBSA participaba Enrique Prieto Garnacho, empresario salmantino de coloniales y destacado importador de bacalao, mientras Federico Heredia, uno de los principales comercializadores catalanes de bacalao, presidía el Consejo de Administración de COPIBA. Finalmente, sus dimensiones empresariales eran muy superiores a las del resto de las empresas pesqueras; en aquellas regiones donde se asentaban, ocupaban lugares relevantes en el ranking de las mayores sociedades no financieras: en 1955, PYSBE, con un capital social de 72 millones de pesetas, se situaba en el puesto vigésimo cuarto de las mayores empresas del País Vasco, mientras PEBSA y COPIBA, con unos activos netos de 80 y $62 \mathrm{mi}-$ llones de pesetas respectivamente, aparecían en el octavo y décimo de las mayores empresas de Galicia. ${ }^{19}$

17. COPIBA, Memorias de varios años.

18. Sinde et al. (2002).

19. Torres (2006), p. 231; Carmona y Alonso (2006), p. 308. 
En definitiva, el conjunto de intervenciones y regulaciones de la política de «condicionamiento industrial» implantada por el franquismo acabó creando en la actividad bacaladera, al igual que en otras ramas industriales, una clara situación monopolística. ${ }^{20}$ La farragosa y arbitraria normativa constituyó una "poderosa barrera legal» de entrada a la actividad, permitiendo a estas empresas adquirir una considerable escala de producción y mantener cuotas de mercado muy elevadas, tanto en bacalao desembarcado como transformado. Aunque su poder de mercado se redujo desde los años cincuenta, especialmente tras la oleada liberalizadora que siguió al Plan de Estabilización de 1959, se mantuvieron hasta su desaparición como empresas dominantes en el sector. A mediados de los años sesenta sus desembarcos de bacalao verde aún representaban la mitad del total y su peso en el procesado seguramente era mayor.

Estos factores adquirieron relevancia cuando los armadores de parejas de altura, dedicados tradicionalmente a la captura de merluza en los bancos del Gran Sol y Canarias, decidieron reorientarse hacia la actividad bacaladera. ${ }^{21}$ Al finalizar la guerra mundial esta flota se había beneficiado de unas capturas excepcionales, por la veda forzosa impuesta durante los años del conflicto; sin embargo, desde 1948, los rendimientos comenzaron a declinar por una situación de sobrepesca, lo que arrastró a esta rama y a la construcción naval a una larga y profunda crisis. De ahí que el segmento más moderno de estas parejas de altura, que también se había transformado con ayudas del Crédito Naval, buscara solucionar sus dificultades participando en la pesca de bacalao. En 1949, la llegada de la pareja Rande-Rodeira, de la empresa Alvamar S.A., a los fondos de Terranova mostró el camino al resto de la flota. ${ }^{22}$

No obstante, las parejas tuvieron que salvar algunos obstáculos, pues la reserva legal de la pesca de bacalao para las grandes empresas las obligó a efectuar tediosas gestiones ante las autoridades. A comienzos de 1950, la solicitud enviada por Alvamar S.A. a diferentes instancias oficiales, dejó patentes las barreras de entrada impuestas por una restrictiva legislación, criterios arbitrarios y prácticas administrativas gratuitas. La petición culminaba una estrategia promovida con diversas empresas pesqueras, la Federación de Armadores y diversas entidades portuarias (cooperativas y frigoríficos) para acometer de forma eficiente la pesca, transformación y comercialización del bacalao mediante una sociedad o una acción cooperativa. Aunque inicialmente los trámites realizados resultaron infructuosos, la situación de crisis

20. Pires (2003), pp. 125-128.

21. El arte de pareja también consiste en una red con forma de bolsa cónica y malla progresivamente más tupida, dotada en su boca con cables y flotadores. En este caso, la apertura lateral de la red se consigue mediante la tracción de dos embarcaciones navegando en paralelo al mismo tiempo.

22. Correspondencia Domínguez Macaya. 
pesquera y la acusada escasez de alimentos contribuyeron a acentuar las presiones ante los diversos organismos y acabaron forzando el cambio. ${ }^{23}$

Los obstáculos comenzaron a removerse desde 1949. En julio se decretó la libertad de comercio de pescado fresco y de bacalao, fresco, verde o salado; poco después se suprimió la obligación de industrialización forzosa de este pescado, liberalizándose su procesado y venta, permitiendo la entrada de nuevos agentes en la actividad salazonera y, algo más tarde, se modificaron los trámites necesarios para el suministro de víveres, combustibles y pertrechos así como el sistema salarial de retribución en las parejas ${ }^{24}$. Este conjunto de cambios normativos tendió a suavizar el régimen de monopolio existente en la actividad bacaladera, al menos en su fase de captura. ${ }^{25}$ En 1950, junto a 22 bous de las empresas bacaladeras nacionales, participaron en la campaña del bacalao 34 parejas y 5 tríos, y, al año siguiente, 112 barcos pareja, 7 tríos y 24 bous. ${ }^{26}$ Con el inicio de la explotación de los fondos de Terranova se abría la que Paz Andrade definió como «segunda etapa de expansión de la pesca española», caracterizada por el desarrollo de la pesca de gran altura y que llevó a primer plano el problema de los costes de producción y la escala de las empresas armadoras. ${ }^{27}$

El poder de mercado de las grandes empresas también afectaba directamente a la fase comercializadora. Las parejas temían una eventual guerra comercial entre ambas ramas bacaladeras, en la que quedarían en desventaja si PYSBE decidiera «lanzar al mercado género a bajo precio». De hecho, el fracaso de los intentos de la Federación de Armadores de Buques de Pesca para la construcción de una planta de secado industrial y las dificultades para adaptar a ese fin ciertas instalaciones portuarias (MEIPI en Pasaia, Consorcio de Trincherpe o Frigoríficos Vigo) planteó abiertamente el problema de la comercialización del bacalao. De ahí que las primeras alternativas fueran venderlo fresco en lonja o verde a las factorías de PYSBE o COPIBA y, desde 1955, a MAR S.A., o a pequeños secaderos, para su venta posterior mediante una red de agentes. ${ }^{28}$

23. Correspondencia Domínguez Macaya.

24. BOE, 8/7/1949; 1/9/1949; 4/2/1950; 18/3/1950; Urrutia (2003); correspondencia Domínguez Macaya.

25. Oya (1976).

26. EP (1950-1951).

27. Paz Andrade (1967 y 1973). Muchos de los problemas relacionados con la escasa dimensión de las parejas, como el almacenaje del pescado o la sal, se resolvieron en 1952 cuando se autorizó el uso de depósitos en Saint-Pierre hasta su envío a España, lo que permitía un aumento del tiempo de faena, de la producción y un ahorro en combustible. BOE, 34, 3/2/1952; López Losa (2008); correspondencia Domínguez Macaya.

28. Correspondencia Domínguez Macaya, 3/7/1950; BOE, 19/9/1953. 


\section{La expansión y sus condicionantes: 1950-1970}

La pesca del bacalao en parejas recibió un fuerte impulso a partir de enero de 1948, al orientarse el Crédito Naval hacia el segmento de flota de mayor desplazamiento y potencia; $150 \mathrm{TRB}, 10$ nudos de velocidad y 5.000 millas de radio de acción. La normativa del crédito estimuló la construcción de barcos de mayores arqueos, cascos de acero y motor diésel, mientras muchos barcos de acero construidos en los cuarenta fueron adaptados para el salado a bordo, mediante alargamientos de eslora y redistribución de bodega. ${ }^{29}$ Con todo, durante los años cincuenta la actividad bacaladera giró más sobre los grandes bous que en torno a las parejas (gráfico 2). La flota de las empresas bacaladeras nacionales alcanzó su máximo en 1959; en ese año PYSBE poseía 16 bous, todos con motores diésel y un arqueo total de 20.243 TRB; la de PEBSA ascendía a 12 barcos, con 15.816 TRB, manteniéndose estable la de COPIBA. ${ }^{30}$

Por el contrario, tanto el número de parejas como su arqueo alcanzaron el máximo en 1951 sin recuperarse hasta 1958. La inadaptación de buena parte de las unidades a las complejas dificultades planteadas por la pesca del bacalao enfrió la euforia inicial, obligándolas a retornar a sus caladeros habituales de Gran Sol y Canarias. Las que se mantuvieron en esta pesquería

GRÁFICO 2 - Flota bacaladera española, según modalidad de pesca

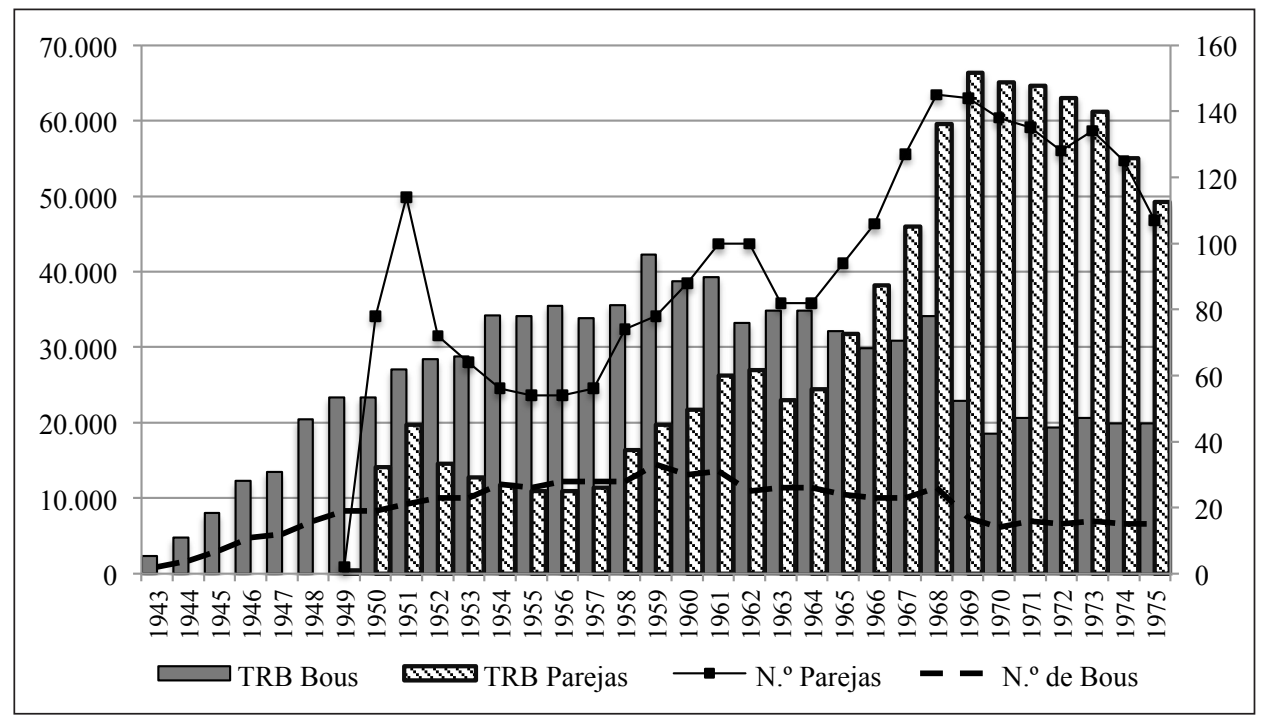

Fuente: Elaboración propia a partir de EP y Anuario de Pesca Marítima (en adelante APM).

29. Sinde et al. (2002).

30. EP (1959). 
fueron las más modernas: casco de acero, motor diésel, arqueo superior a la media, mayor potencia, mayor radio de acción y capacidad de salar a bordo. Aunque generalmente pertenecían a casas armadoras tradicionales, de dimensiones empresariales limitadas, con flotas de dos o tres parejas, también se constata la participación de nuevos actores vinculados a los negocios marítimos pesqueros, principalmente conserveros y constructores navales. ${ }^{31}$

Enmarcada en la liberalización de la economía española de la década de los sesenta, la Ley de renovación y protección de la flota pesquera, promulgada en 1961, contemplaba variadas intervenciones del Estado: primas a la construcción naval, desgravaciones y exenciones fiscales y una actuación sobre el Crédito Naval. Buscaba elevar el consumo de pescado, hacer despegar sus exportaciones y crear «una flota eficiente y moderna, apta para realizar abundantes capturas con mínimos costes» en caladeros alejados. A lo largo de la década se fueron endureciendo las condiciones para la concesión de los créditos, se redujeron los largos plazos de amortización, de veinte a ocho años, y los intereses se incrementaron, del 4 al 5,85\%, pero el impulso del Estado se mantuvo: de cada 100 pesetas invertidas en la construcción de nuevas embarcaciones 83 procedieron de diversas subvenciones oficiales y sólo 17 procedieron de inversión privada. ${ }^{32}$ Esta actuación redujo a niveles mínimos el coste de la inversión inicial, eliminando una de las barreras de entrada al sector; muchos armadores pudieron afrontar las elevadas exigencias financieras que representaba la adquisición de una unidad pesquera. Sin embargo, el retraso en la llegada de la ayuda financiera estatal demoró hasta 1964 la botadura de los primeros barcos subvencionados con cargo al Crédito Naval y, aunque en un primer momento el crédito se orientó hacia la flota congeladora, a finales de la década la tendencia se corrigió. ${ }^{33}$

Impulsada por la ayuda estatal, la «ruptura del modelo autárquico en la construcción naval» provocó un rápido e intenso desarrollo de la flota pesquera. ${ }^{34}$ Se construyeron barcos de mayores dimensiones, con nuevas líneas y estructuras, cubierta cerrada, primero parcial y luego totalmente, se introdujo el arrastre por popa sustituyendo al lateral ${ }^{35} \mathrm{se}$ incorporaron instalaciones de congelación a bordo, procesado para la elaboración de aceites y harinas, e instrumentos más avanzados de navegación y detección. Además se transformaron sus tradicionales artes de arrastre, reemplazando las fibras vegetales por fibras artificiales, de mayor resistencia, menor peso y mayor tamaño. ${ }^{36}$

31. Giráldez (2005); Sinde (2000).

32. González Laxe (1983), pp. 68-69.

33. Ibíd., p. 269.

34. Carmona y Nadal (2005), p. 294.

35. El arte de arrastre por popa es similar al de los bous, la diferencia radica en el procedimiento de largado y recogida que se efectúa por la popa del barco, que está dotada de una rampa, pórtico y diversos dispositivos para facilitar una maniobra muy mecanizada.

36. García-Orellán (2004), pp. 86-87, 206; Landeta (1996); Eiroa (2002). 
TABLA 1 - Principales magnitudes de la pesca del bacalao

\begin{tabular}{cccccc}
\hline & $\begin{array}{c}\mathbf{N}^{\circ} \mathbf{d e} \\
\text { barcos }\end{array}$ & TRB & $\begin{array}{c}\mathbf{N}^{\circ} \text { de } \\
\text { tripulantes }\end{array}$ & $\begin{array}{c}\text { Capturas } \\
(\mathbf{T m})\end{array}$ & Miles de pts. \\
\hline 1963 & 108 & 57.838 & 3.243 & 224.967 & 1.524 .044 \\
\hline 1964 & 108 & 59.319 & 3.258 & 230.500 & 1.537 .254 \\
\hline 1965 & 118 & 63.931 & 3.487 & 234.009 & 1.602 .633 \\
\hline 1966 & 129 & 67.980 & 3.425 & 241.208 & 1.651 .932 \\
\hline 1967 & 150 & 76.868 & 4.160 & 289.736 & 1.984 .734 \\
\hline 1968 & 171 & 93.705 & 4.847 & 341.311 & 2.337 .891 \\
\hline 1969 & 161 & 89.205 & 4.414 & 293.972 & 2.296 .918 \\
\hline 1970 & 152 & 83.605 & 4.053 & 276.007 & 2.675 .279 \\
\hline 1971 & 151 & 85.194 & 4.010 & 261.547 & 3.557 .636 \\
\hline 1972 & 143 & 82.356 & 3.682 & 224.685 & 3.173 .412 \\
\hline 1973 & 150 & 81.763 & 3.967 & 165.747 & 2.499 .453 \\
\hline 1974 & 140 & 74.919 & 3.622 & 167.015 & 3.061 .443 \\
\hline 1975 & 122 & 69.133 & 3.238 & 115.035 & 1.950 .000 \\
\hline
\end{tabular}

Fuente: Elaboración propia a partir de EP y APM.

En 1968 se alcanzó el máximo de la pesquería, tanto por número de barcos operativos, como por arqueo, capturas o tripulantes (tabla 1). Ese año el número de bous ascendía a 26, todos construidos antes de 1960, salvo 3 que incorporaban la tecnología naval más reciente. Por su parte, la flota de parejas experimentó un fuerte crecimiento y una profunda transformación: en 1968 llegaba a 145 barcos con 60.000 TRB. Aunque mantenía un porcentaje anticuado, mayoritariamente se habían construido en la década de los sesenta y un segmento muy significativo (26\%) después de 1965, con un arqueo unitario muy superior al resto $(30 \%)$ y la tecnología más novedosa. Sin embargo, en 1968, el ranking de empresas del sector pesquero lo seguían encabezando PYS$\mathrm{BE}$, con 16 barcos y 20.882 TRB, y PEBSA, con 11 barcos y 14.717 TRB. ${ }^{37}$

Sin entrar a valorar la fiabilidad de la estadística española sobre la pesca de bacalao, tema del que se ha ocupado detenidamente López Losa, parece evidente la multiplicación de las capturas con el incremento de la actividad. ${ }^{38}$ El despegue de la producción fue muy rápido (gráfico 3): la media del quinquenio 1946-1950 se duplicó en 1951-1955, y a pesar de ralentizarse en la segunda mitad de los cincuenta, se recuperó en 1961-1965, creciendo más de un 50\% respecto al anterior; también el promedio 1966-1970 fue un 30\% superior; el máximo se alcanzó en 1968, cayendo desde entonces. Ya en 1965 el in-

38. López Losa (2001). 
GRÁFICO 3 - Capturas de bacalao efectuadas por la flota española (Tm)

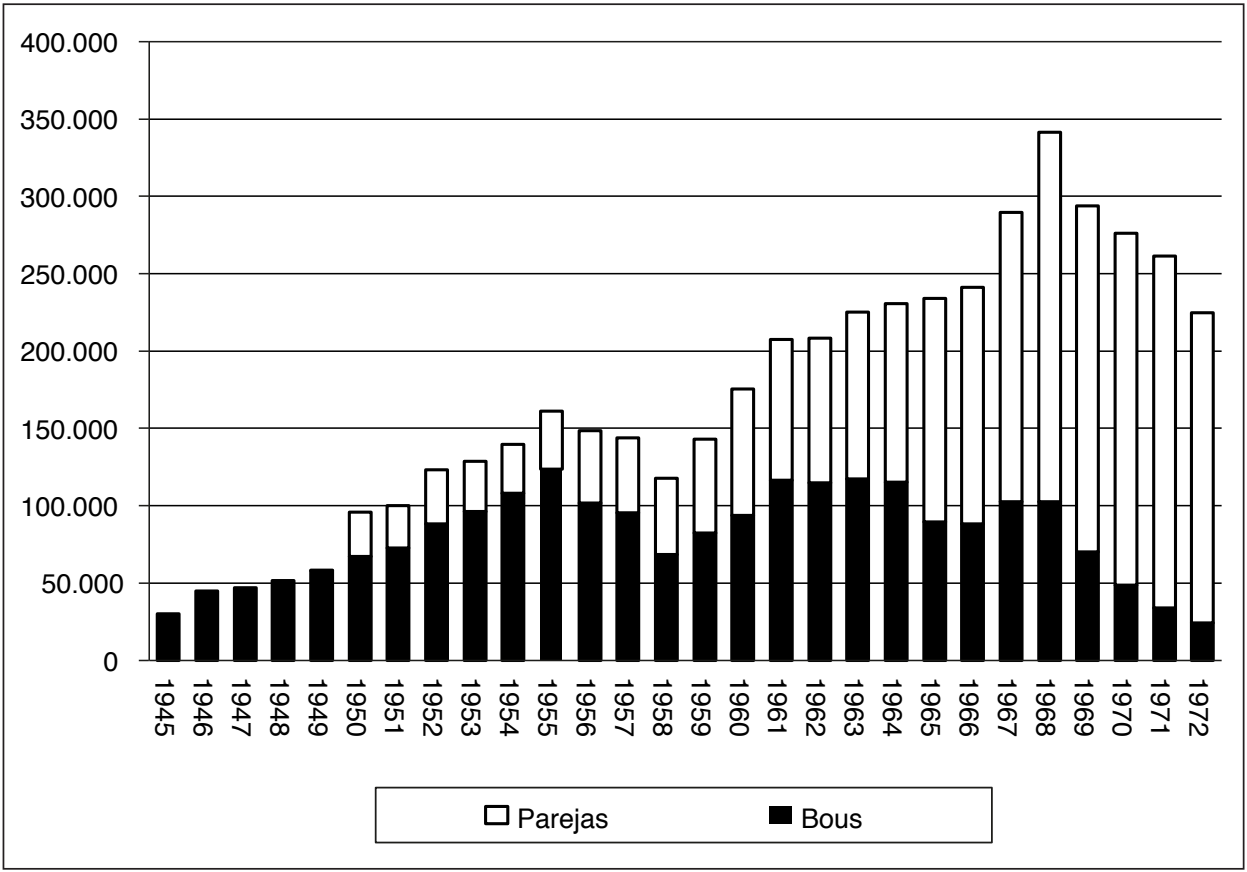

Fuente: Elaboración propia a partir de EP y $A P M$.

forme de la ICNAF avisaba de que la pesquería del bacalao en casi toda el área del Atlántico noroccidental estaba llegando a su rendimiento máximo, «por lo que no pueden esperarse aumentos de las capturas en caso de intensificarse aún más dicho esfuerzo». ${ }^{39}$

Las capturas de bacalao reflejaron los cambios en la estructura de la flota. Hasta comienzos de los años sesenta se basaron fundamentalmente en las de los bous, pero desde mediados de la década su declive se aceleró: en 19601964 representaron el 53\% y en 1965-1969 sólo el 33\% y después apenas superaron el $10 \%$. Frente a esta decadencia de los bous, las parejas se convirtieron en las unidades pesqueras por excelencia; su número de barcos, su arqueo total y su arqueo medio se incrementaron progresivamente. Su éxito también derivó de una mejor dotación tecnológica de navegación y pesca, que las equiparó con los bous. Esto permitió que intensificaran sus trabajos fuera del Gran Banco de Terranova, hacia la península de Labrador y Nueva Escocia, con fondos más duros y áreas menos explotadas, logrando aumentar los rendimientos. Al mismo tiempo, la nueva maquinaria de procesado incorporada (descabezadoras, lavadoras o quitaespinas) favoreció la reducción de las tri-

39. Rodríguez Martín (1965). 
TABLA 2 - Evolución de los rendimientos según tipo de flota

\begin{tabular}{ccccc}
\hline & Tm/TRB & Tm/TRB & Tm/tripulante & Tm/tripulante \\
\hline & Bous & Parejas & Bous & Parejas \\
\hline $1960-1964$ & 3,10 & 4,01 & 68,55 & 53,62 \\
\hline $1965-1969$ & 3,03 & 4,00 & 69,99 & 68,78 \\
\hline $1970-1974$ & 1,84 & 3,39 & 46,06 & 69,41 \\
\hline
\end{tabular}

Fuente: Elaboración propia a partir de APM y EP.

pulaciones, por eliminación de la mayoría de los marineros especializados, a excepción de los saladores. ${ }^{40}$

Los rendimientos de las parejas fueron sensiblemente superiores a los de los bous durante buena parte de los años sesenta (tabla 2). Su ventaja se acentuó con la mayor rentabilidad derivada de la calidad del bacalao capturado, que partía de su tamaño, cuestión de gran importancia comercial, y de las retribuciones pagadas a los trabajadores.

La clasificación a bordo se efectuaba según su tamaño: grande, cuando superaba $\operatorname{los} 2,1 \mathrm{~kg}$; mediano, cuando superaba $1,1 \mathrm{~kg}$ y pequeño si no llegaba a este peso. ${ }^{41}$ El promedio de bacalao pequeño capturado por la flota española representó en el quinquenio 1962-1966 el 85\% del total, moderado en 1967-1971 al caer hasta el 76\%, por el mayor protagonismo de las parejas, con mayores capturas de bacalao grande y mediano (gráficos 4 y 5). Así, los bous capturaron en promedio sólo un $6 \%$ de bacalao grande y mediano frente al $94 \%$ de bacalao pequeño, mientras las parejas lo hicieron en un 26 y $74 \%$ respectivamente. También las especies asociadas, menos valorizadas que el bacalao, caso del eglefino o el palero, fueron menos importantes para las parejas que para los bous e incluso se redujo a lo largo de los años sesenta por razones comerciales. ${ }^{42}$ Este conjunto de factores incidieron directamente sobre los precios y la política de comercialización de las grandes empresas bacaladeras, afectando decisivamente a sus ingresos. Desde 1968, PEBSA hizo constar año tras año el declive de su posición en el mercado interior, tanto por una continuada reducción del consumo de bacalao como porque «no consume más que tamaños grandes y medianos y como sabéis los de los bous son tamaños pequeños, que sólo se pueden vender para la exportación». ${ }^{43}$

Así pues, la actividad bacaladera experimentó una notable transformación desde finales de los años sesenta, al evidenciarse el declive del caladero de Terra-

40. García Orellán (2004), pp. 203-204.

41. Urrutia (2003);Alemany (1973).

42. Rodríguez Martín (1965 y 1967); Oya (1976).

43. PEBSA, Libro II de Actas de la Junta General de Accionistas, 31/12/1968. 
GRÁFICO 4 - Clases de bacalao desembarcado por los bous (\%)

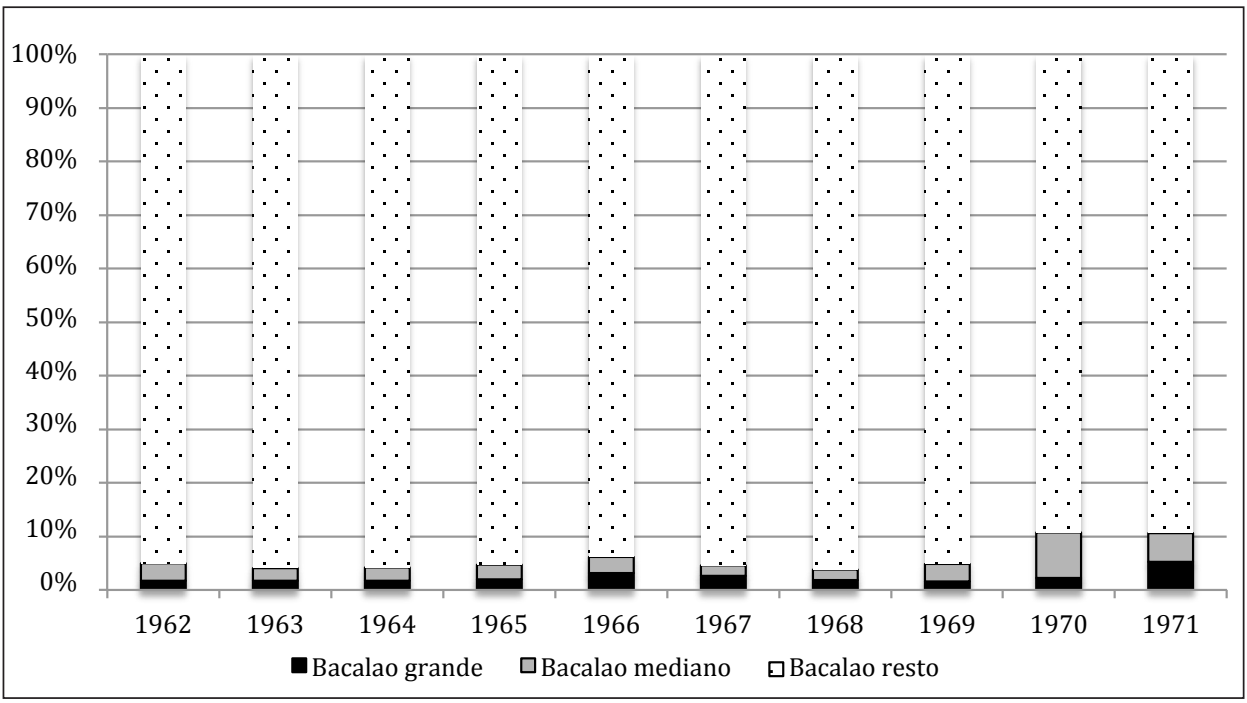

Fuente: Elaboración propia a partir de Alemany (1973).

nova y cuando el desarrollo de la congelación en la pesca mostraba las posibilidades de una nueva línea de negocio, anunciando una nueva forma de empresa pesquera, multiespecífica y multinacionalizada.$^{44}$ Las grandes empresas comenzaron a verse afectadas por graves problemas en la fase productiva y comercializadora. COPIBA, con una flota limitada y escasamente dimensionada, fue absorbida por PESCANOVA en 1964. PYSBE suspendió pagos, cerró sus plantas procesadoras y, en 1974, amarró su flota. ${ }^{45}$ PEBSA también atravesó en la segunda mitad de los sesenta por un período de acumulación de pérdidas; en 1971, tras la muerte de Pedro Barrié de la Maza, se fusionó con Agrupesca para acabar integrada en el grupo Pleamar, un holding alimentario muy diversificado. ${ }^{46}$

La decadencia de estas empresas reflejaba la necesaria modernización constatada a comienzos de los años setenta. Como indicaba el III Plan de Desarrollo (PDES), la flota bacaladera adolecía de ser: «... relativamente vieja, lo cual repercutía en una doble vertiente: bajo rendimiento como consecuencia de la falta de mecanización y poco aprovechamiento de su esfuerzo pesquero». Se hacía necesaria su renovación, con la sustitución de los barcos de mayor edad por nuevas unidades bacaladeras, «dotadas de equipos adecuados para el tratamiento y preparación del pescado», congelado, salado o ela-

44. Giráldez (2008).

45. BOE, 24/12/1973.

46. PLEAMAR, Memoria 1975. 
GRÁFICO 5 - Clases de bacalao desembarcado por las parejas (\%)

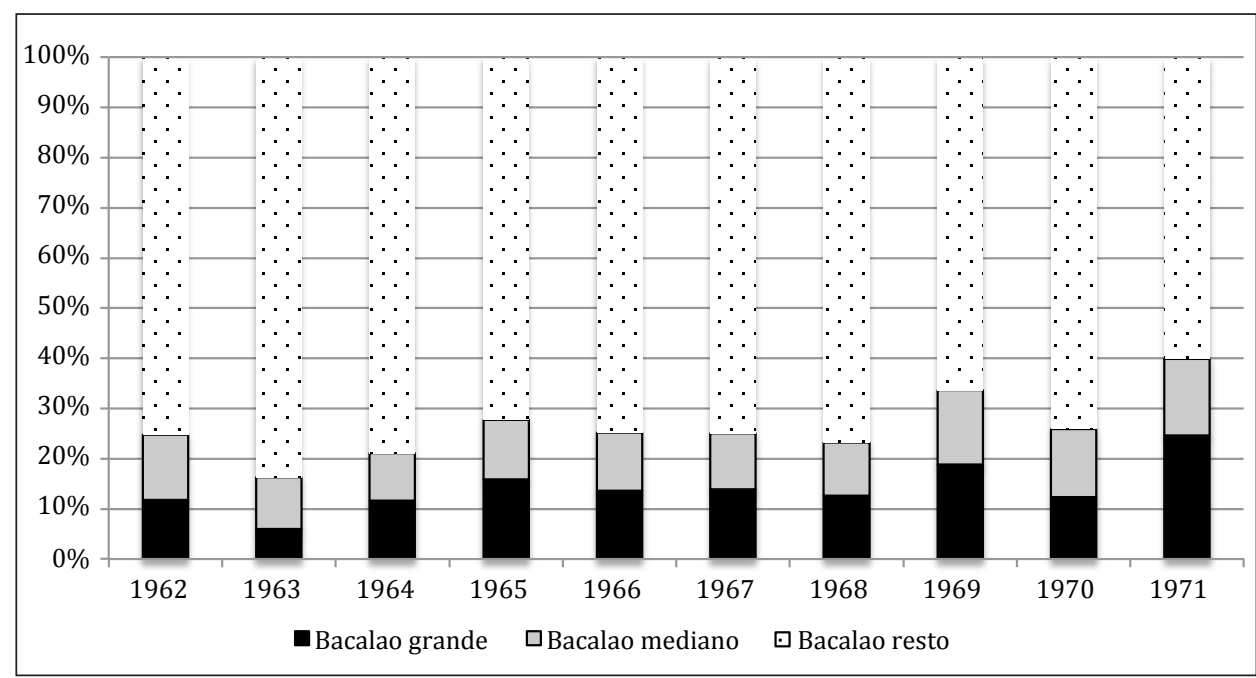

Fuente: Elaboración propia a partir de Alemany (1973).

boración de subproductos. ${ }^{47}$ De hecho, a finales de los años sesenta, la flota de parejas completó su transformación, abandonando las formas del arrastre lateral en favor de las de arrastre por popa e incorporando la tecnología más novedosa. Desde 1967 las parejas aumentaron considerablemente su arqueo y las formas clásicas tendieron a reducir su peso en la flota. ${ }^{48}$

En 1975 la mayoría de las parejas se concentraba en el intervalo de edad de diez años, es decir, habían sido construidos en la segunda mitad de los sesenta (gráfico 6). Esto se comprueba en número de barcos $(64 \%)$, TRB $(73 \%)$ o potencia $(72 \%)$, su media de arqueo ascendía a 539 TRB, su potencia a $1.200 \mathrm{HP}$ y su tripulación a 23,83 hombres. Su arqueo era un $30 \%$ mayor y su potencia casi un $25 \%$ respecto a los construidos diez años antes, aunque el número de tripulantes era un $9 \%$ inferior.

Aunque la flota de bous aún mantenía una cierta presencia en 1975, no era tanto por su número, apenas quince unidades, sino por su arqueo un $30 \%$ del TRB total. La mayoría pertenecía a la flota de PEBSA, ampliada tras su integración con PIEAMAR y compuesta por nuevos ramperos mixtos, congeladores y salazoneros, así como por aquellos antiguos bous que no se habían desguazado o transformado en parejas. En todo caso, su vida útil como bacaladeros fue muy limitada, no tardando buena parte de ellos en destinarse a otras pesquerías.

48. Eiroa (1997), pp. 217-218. 
GRÁFICO 6 - Distribución de la flota de parejas de 1975 por grupos de años

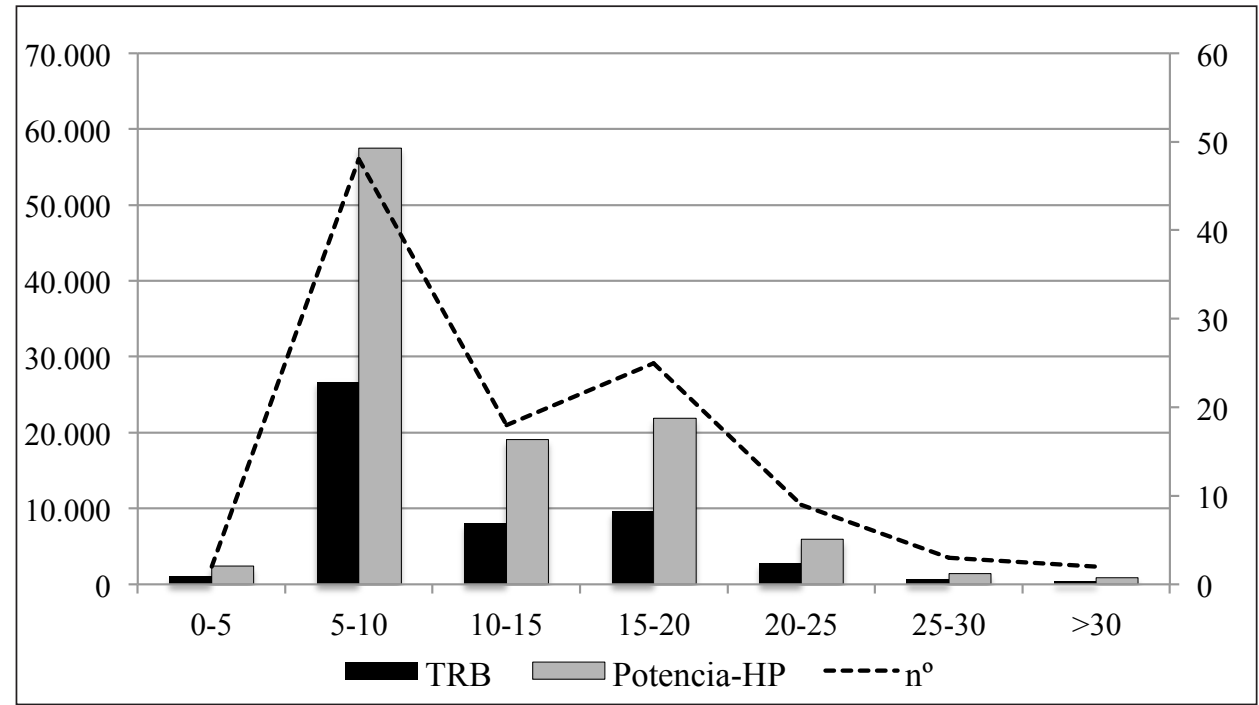

Fuente: Elaboración propia a partir de APM, 1975.

GRÁFICO 7 - Distribución de la flota de bous de 1975 por grupos de años

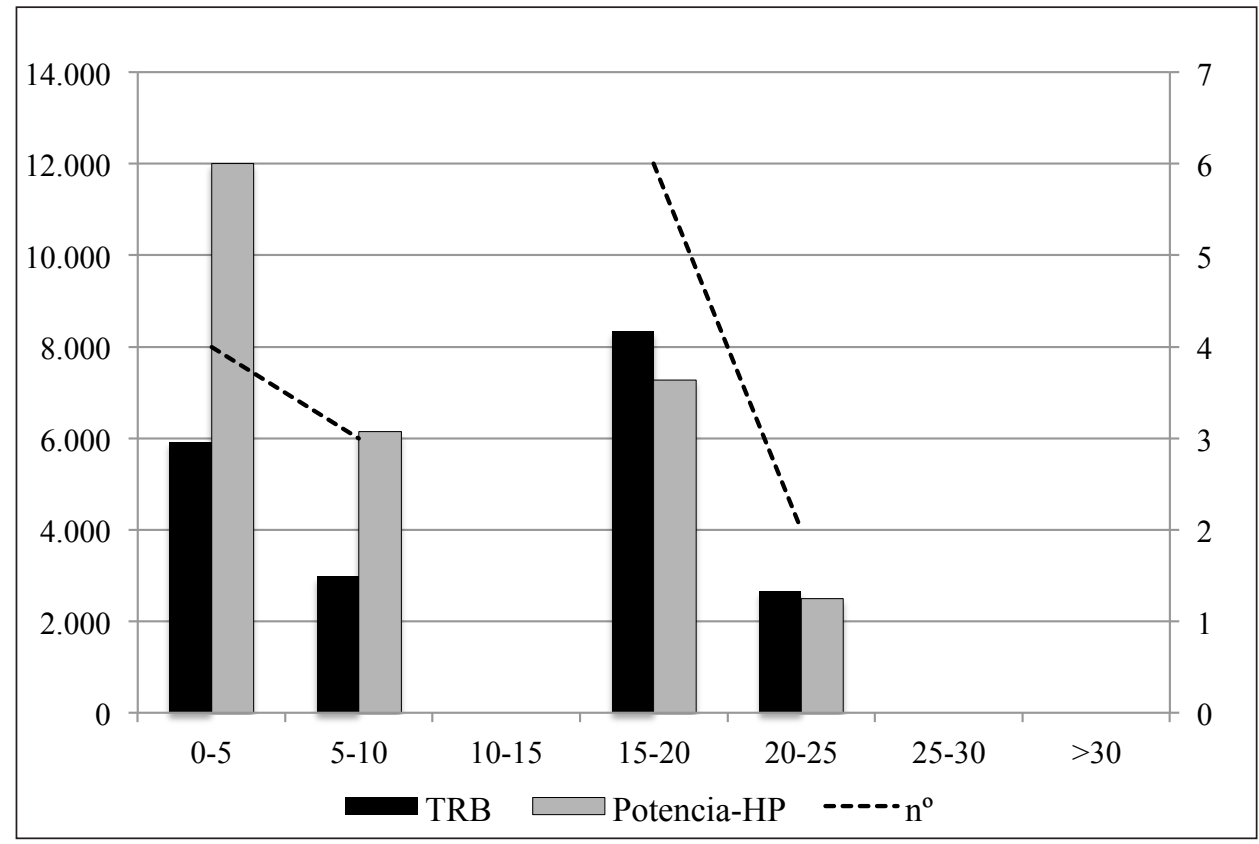

Fuente: Elaboración propia a partir de APM, 1975. 


\section{La industria transformadora}

La industria de transformación de bacalao estuvo muy concentrada geográficamente. Una concentración que se fue reduciendo desde mediados de la década de 1960 y más claramente en la de 1970. Esto se constata tanto por medio de los datos de descargas de bacalao recogidos en las Estadísticas de pesca como en la información sobre producción en salazón proporcionada por Industrias derivadas de la pesca.

Las cifras disponibles para 1952-1953 indican que más del 99\% del bacalao desembarcado en verde lo hizo en tres provincias: Gipuzkoa (37\%), Pontevedra (35\%) y A Coruña (28\%), lo que se explica por la concentración de la actividad en muy pocas empresas, caso de PYSBE, que tenía situadas sus factorías en A Coruña y Ferrol, o de COPIBA y MAR S.A., localizadas en Vigo.

Esta distribución se consolidó a la par del desarrollo de la propia actividad. Entre 1963 y 1975 las descargas se mantuvieron concentradas en Gipuzkoa (51\%), A Coruña (31\%) y Pontevedra (15\%). Los puertos principales fueron Pasaia, A Coruña, con más del 20\%, y Ferrol, con el 10\%, aunque desde 1964 experimentó un continuado declive. Por su parte, Vigo, que ocupaba a comienzos de la década el cuarto lugar, con un discreto $7 \%$, incrementó desde 1968 sus desembarcos, llegando al 24\% en 1975. Los cambios en la composición de la flota, con el auge de las parejas, favorecieron a los puertos de Pasaia y Vigo, especialmente en los primeros años setenta, pero también beneficiaron a ciertos puertos de la ría de Arousa, como Santa Uxía de Ribei-

GRÁFICO 8 - Distribución de las descargas de bacalao por puertos (1963-1975)

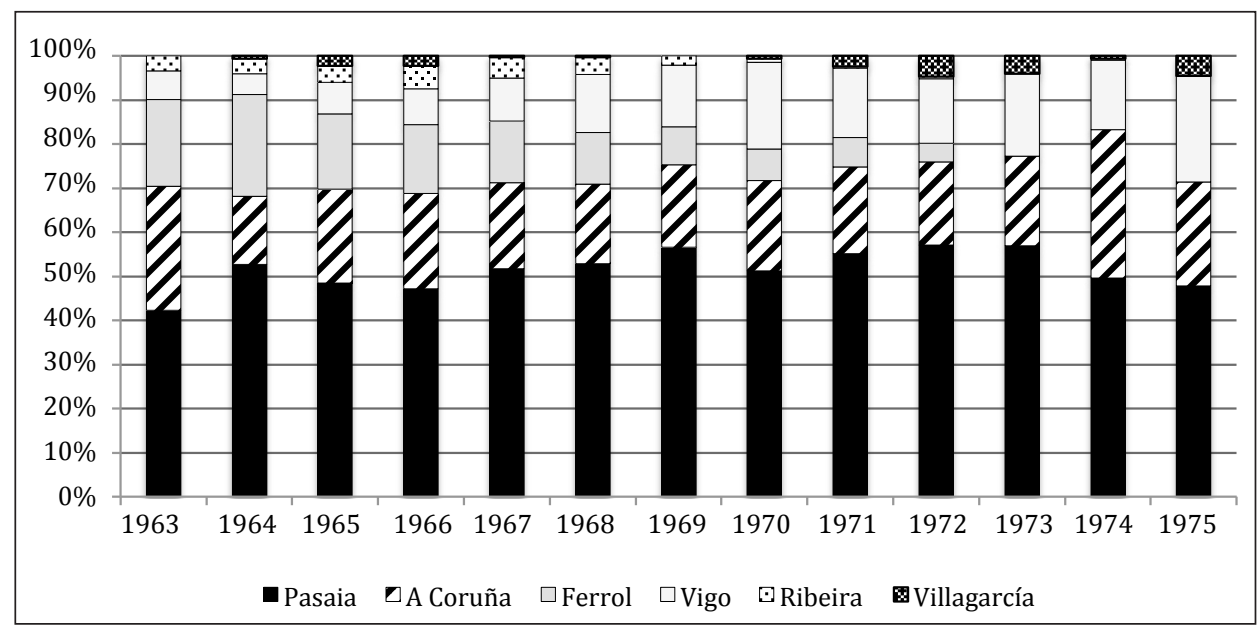

Fuente: Elaboración propia a partir de EP y $A P M$. 
GRÁFICO 9 - Producción de bacalao salado en España (Tm)

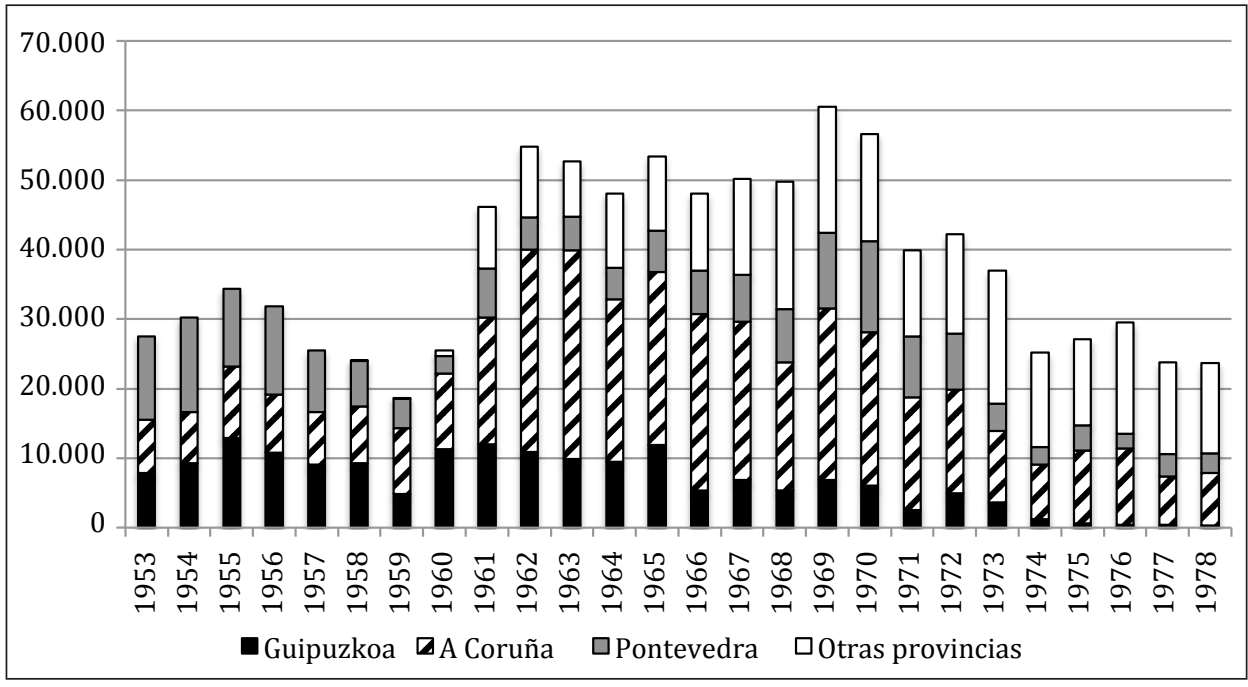

Fuente: Elaboración propia a partir de Industrias derivadas de la pesca.

ra, Pobra do Caramiñal o Vilagarcía en los cuales, aún sin tener un peso importante en el total $(3 \%)$, se consolidó una industria transformadora de cierta entidad. ${ }^{49}$

A partir de 1959 la suavización de las condiciones de establecimiento industrial y, desde 1963, la liberalización de numerosas actividades, entre las que se encontraba la producción de semiconservas y salazones de pescado, permitió prescindir de la autorización administrativa previa para la apertura o ampliación de instalaciones, favoreciendo el desarrollo de la rama procesadora de bacalao. ${ }^{50}$ Las estadísticas de producción de bacalao en salazón, de Industrias derivadas de la pesca (gráfico 9), permiten aproximarse a los cambios suscitados. Lo primero que destaca es el desplazamiento de las provincias de Gipuzkoa y Pontevedra por A Coruña, que adquirió una importancia abrumadora: entre 1959 y 1971, el promedio de la producción en A Coruña ascendió al 45\% del total. Sin duda, la inauguración en 1959 de la gran factoría de PEBSA, junto a la de PYSBE en Ferrol y otras de menores dimensiones instaladas en A Coruña y Ribeira, explican el predominio de esta provincia. Por otra parte, se constata el efecto de la liberalización de establecimiento sobre esta rama, la aparición de numerosas provincias con instalaciones salazoneras, que acabarán por dominar la producción en los primeros años setenta.

49. Alemany (1973); Oya (1976); Tolosa (1984).

50. Pires (2003); Buesa y Pires (2002). 
El Catálogo de Empresas del Sindicato de la Pesca de 1969 permite profundizar en esta transformación. ${ }^{51}$ Numéricamente la industria aparece constituida por 52 establecimientos y 2.912 trabajadores, geográficamente distribuidos por quince provincias. ${ }^{52} \mathrm{~A}$ Coruña, con 11 factorías y 882 trabajadores (lo que representa el 21 y el $30 \%$, respectivamente) era la principal, seguida por Gipuzkoa, 10 y 831 (19 y $28 \%$, respectivamente) y Pontevedra, 2 y 332 (4 y 11\%, respectivamente). El peso alcanzado por estas tres provincias se debe a que en ellas radicaban los principales puertos de desembarco de bacalao. Por otra parte, destaca el desarrollo alcanzado por el procesado en provincias del interior: en 1970-1974 representaban el 40\% del total, concentradas sobre todo en Navarra, 9 plantas y 155 trabajadores (17 y 3\%, respectivamente); Bizkaia, 3

TABLA 3 - Empresas transformadoras de bacalao en 1969 (más de 50 empleados)

\begin{tabular}{lllc}
\hline Provincia & \multicolumn{1}{c}{ Nombre } & Localidad & Ocupados \\
\hline A Coruña & PYSBE & Ferrol & 431 \\
\hline Gipuzkoa & PYSBE & Pasaia & 363 \\
\hline A Coruña & PEBSA & A Coruña & 200 \\
\hline Pontevedra & Motopesqueros de Altura Reunidos (MAR S.A.) & Vigo & 312 \\
\hline Gipuzkoa & José Antonio Lasa S.A. & San Sebastián & 174 \\
\hline Bizkaia & Hijos de José Serrats S. R. C. & Bermeo & 100 \\
\hline Gipuzkoa & Hijos de José Serrats S. R. C. & Pasaia & 30 \\
\hline Gipuzkoa & Muelles e Instalaciones de la Pesca e Industrias & Pasaia & 98 \\
\hline Burgos & SA (MEIPI) & Miranda del Ebro & 85 \\
\hline A Coruña & Eusebio Bonjoch Salafranca & A Coruña & 75 \\
\hline Bizkaia & Trueba y Pardo SA & Bilbao & 74 \\
\hline Sevilla & Trueba y Pardo SA & Sevilla & 22 \\
\hline Bizkaia & Industrial Bacaladera Española S.A. & Bilbao & 72 \\
\hline Navarra & Comercial Ibérica de Pescados (CIPESA) & Pamplona & 65 \\
\hline A Coruña & Hija de Emilio Colomer & Ribeira & 60 \\
\hline Melilla & Ángel Herrero Guillén & Melilla & 60 \\
\hline Melilla & Francisco Herrero Guillén & Melilla & 59 \\
\hline Soria & José María Suescún Esquiza & Almazán & 54 \\
\hline Gipuzkoa & ISLAMAR (José Sarasola Emazabel) & Oiartzun & 50 \\
\hline
\end{tabular}

Fuente: Elaboración propia a partir de Servicio Sindical de Estadística (1969)

51. Servicio Sindical de Estadística (1969). Inexplicablemente esta fuente no incluye a José Antonio Lasa S.A., acaso fruto de un error, pues sí figura en el directorio de empresas de más de cincuenta productores de 1972.

52. Se han excluido los trabajadores del Consorcio Nacional Almadrabero. 
y 246 (8 y 6\%, respectivamente) y Burgos, 2 y 125 (4 y 3\% respectivamente), provincias con una larga tradición de consumo de bacalao y situadas próximas a los puntos de descarga.

Esta fuente también permite observar el acusado carácter dual que mostraba la estructura de la industria. Por un lado, las grandes sociedades que integraban producción y procesado, caso de PEBSA o PYSBE, pero también complejos pesqueros como MAR SA, que agrupaba una importante flota de altura y gran altura, fábrica de hielo, redes, y disponía de sus propios canales de comercialización hasta los mercados finales. Junto a estas existía un grupo de firmas de dimensión intermedia, de entre 75 y 200 trabajadores. Entre ellas aparecen casas armadoras como José Antonio Lasa S.A., que posee una nada despreciable flota de parejas bacaladeras; conserveras como Hijos de José Serrats S. R. C, con establecimientos en Bizkaia y Gipuzkoa y con flota bacaladera propia y frigoríficos, o el consorcio MEIPI, en el que participan importantes empresas pesqueras como Laboa, Ciriza o Andonaegui, y que disponen de fábrica de hielo, almacenes, frigoríficos y otras instalaciones. También, están presentes comercializadores, como Trueba y Pardo SA, principal importador de bacalao antes de la guerra, con plantas en Bizkaia y Sevilla, o Isidoro Pérez Gaitán, de origen navarro y del comercio de comestibles; una presencia que apunta a una integración vertical orientada al abastecimiento del mercado. ${ }^{53}$

Por otro lado, un gran número de empresas inferiores a cincuenta trabajadores, de pequeña o muy pequeña dimensión, que representaban el $80 \%$ del número pero sólo el $20 \%$ de los trabajadores. En este sentido, parece que la liberalización de la actividad provocó una proliferación de pequeñas empresas con escasa capitalización, estructura de costes inadecuada, reducida capacidad productiva y técnicamente mal dotadas. Algo constatado por el II PDES, que apuntaba a la necesidad de favorecerlas mediante el crédito privado y público, incluso a fondo perdido, a través de la constitución de agrupaciones de empresas. ${ }^{54}$ De hecho, los fabricantes gallegos constituyen un buen ejemplo del intento de superar su atomización mediante una actuación conjunta; las tres empresas bacaladeras existentes en la Ría de Arousa (Hija de Pérez Colomer, Tomás Bussoms y COINBA), conocidas como el Grupo Arosa, actuaron colectivamente en la compra de bacalao y, en 1969, junto con dos empresas de A Coruña (Eusebio Bonjoch Salafranca y Arturo Bodelón Nieto) crearon EXBANOSA (Exportadores de Bacalao del Noroeste) para actuar conjuntamente en los mercados de exportación. ${ }^{55}$

53. Barkham y López Losa (1999); Escudero y López Losa (2011); Espido y Giráldez (2015)

54. II PDES (1964), p. 101.

55. Pérez Fariña (1985). 
En todo caso, el importante desarrollo de la industria procesadora que tuvo lugar en los años sesenta, a la par del aumento de las capturas, convirtió a España en uno de los principales productores de bacalao seco. En 1969, con 59.400 t, ocupaba el primer lugar en el ranking mundial y, desde entonces, el segundo, tras Noruega. También en las exportaciones de bacalao ocupó una posición preeminente, sólo aventajada por Noruega. ${ }^{56}$

\section{El comercio exterior de bacalao}

La política autárquica de desarrollo económico del primer franquismo se asentó en una estrategia de sustitución de importaciones y reducción máxima de la dependencia exterior. El radical intervencionismo desplegado por el régimen, con la implantación de autorizaciones administrativas previas y la insuficiencia de medios de pago, sometió a los intercambios internacionales a estrictas restricciones cuantitativas, ajustadas a un férreo control de cambios por la crónica escasez de divisas. Los tráficos de bacalao no fueron ajenos a esta situación, mantuvieron las pautas del conjunto del comercio exterior español.

Las importaciones de bacalao salado y seco, que en el quinquenio 19311935 ascendían a 63.996 t, se redujeron durante la Guerra Civil a sólo 26.356, quedando limitadas durante los años cuarenta en torno a 11.000 anuales. Tuvo lugar «el eclipse en la importación de bacalao»; España desapareció del mercado mundial como principal comprador. ${ }^{57}$

Partiendo de los bajos niveles en los que habían quedado tras la Guerra Civil, entre 1940 y 1974 las importaciones de bacalao volvieron a crecer, haciéndolo a una tasa del 1,14\% anual para el conjunto del período. Sin embargo, esta etapa se caracteriza no tanto por su crecimiento como por sus fuertes oscilaciones; elevadas tasas de crecimiento en ciertos quinquenios y fuertes caídas en otros (tabla 4 y gráfico 10). Los factores que influyeron en estos altibajos fueron diversos. A grandes rasgos, y al margen del comportamiento de las capturas de bacalao, se podría apuntar para las décadas de los cuarenta y cincuenta, la acusada escasez de divisas y el intenso intervencionismo. ${ }^{58}$ Para las de los sesenta y primeros años setenta merecen destacarse los cambios en la política comercial y monetaria (aranceles, fin de los tipos de cambios múltiples o devaluaciones), el aumento y la diversificación de la oferta de alimentos en el mercado interior, favorecedoras de nuevas pautas de consumo y ligadas al desarrollo de las modernas formas de comercialización y distribución

56. FAO (1972 y 1977).

57. Barciela (1989), p. 137.

58. Fuentes (1962); Donges (1976); Pires (2003), (2005); Viñas et al. (1979). 
GRÁFICO 10 - Comercio exterior español de bacalao (Tm)

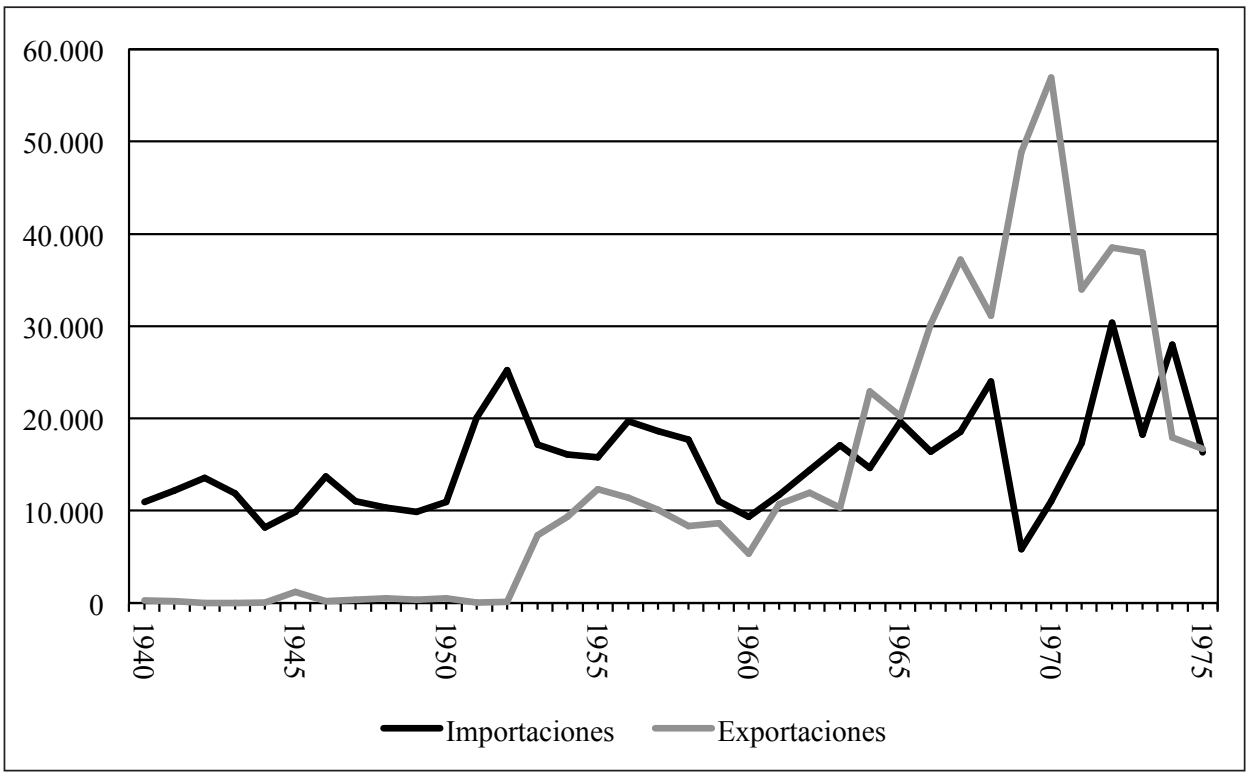

Fuente: Elaboración propia a partir de las ECEE.

TABLA 4 - Importaciones y exportaciones de bacalao. Tasas de crecimiento (\%)

\begin{tabular}{ccc}
\hline Período & Importaciones & Exportaciones \\
\hline $1940-1944$ & $-2,03$ & 31,77 \\
\hline $1945-1949$ & 2,08 & $-15,59$ \\
\hline $1950-1954$ & 7,61 & 89,05 \\
\hline $1955-1959$ & $-9,94$ & $-15,42$ \\
\hline $1960-1964$ & 15,95 & 30,61 \\
\hline $1965-1969$ & $-10,88$ & 22,96 \\
\hline $1970-1974$ & 8,11 & $-21,74$
\end{tabular}

Fuente: Elaboración propia a partir de las ECEE.

minorista, la evolución general de la demanda interna y las medidas económicas de stop and go aplicadas en España en los años sesenta.

El origen de las importaciones varió a lo largo de la etapa; las salazones americanas, de Terranova y Canadá, representaron entre 1940-1949 el 50\% del total, pero entre 1955 y 1969 apenas si llegaron al 12\% y después cayeron drásticamente. Por el contrario, las producciones europeas se hicieron hegemónicas desde la segunda mitad de los cuarenta. El bacalao de Dinamarca, 
GRÁFICO 11 - Distribución de las importaciones españolas de bacalao $(\mathrm{kg})$

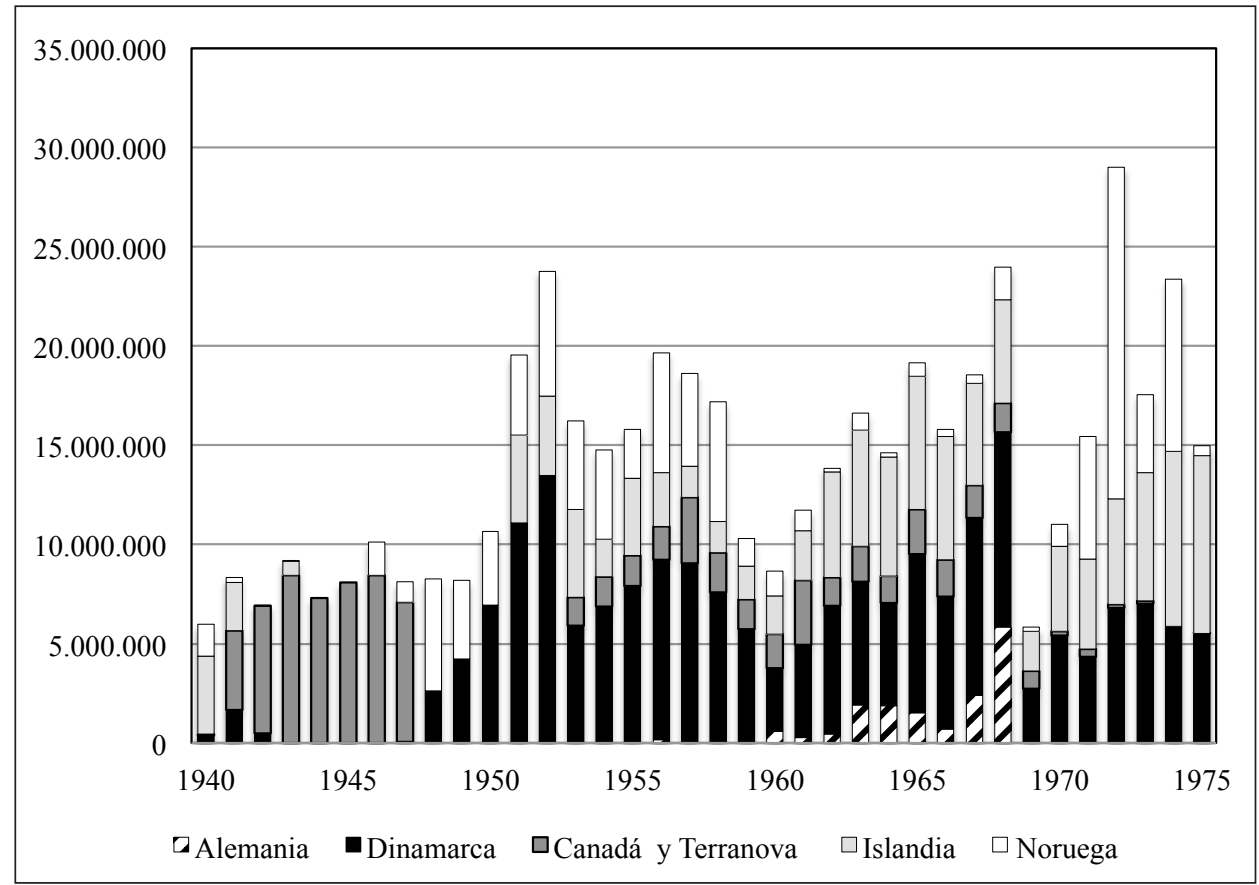

Fuente: Elaboración propia a partir de las ECEE.

en realidad de las Islas Feroe y Groenlandia, dominó las importaciones en los cincuenta (49\%) y sesenta (40\%). El de Noruega llegó al 25\% entre 1945 y 1959 , cayó en los sesenta hasta un $5 \%$, recuperándose después. Por su parte, el de Islandia, que en los años cincuenta rondó el 15\%, alcanzó el 32\% en los sesenta, una década en la que también la República Federal de Alemania orientó hacia España su creciente producción. Entre 1970 y 1974 de Islandia, Noruega y Dinamarca procedieron el $92 \%$ del total de las importaciones españolas de bacalao.

Por su parte, las exportaciones mostraron un fuerte dinamismo, creciendo entre 1940 y 1975 a razón de un 13,2\% acumulativo anual. En la evolución de las exportaciones se pueden diferenciar tres etapas (gráfico 10). La primera abarca hasta 1953, en la que las exportaciones fueron casi inexistentes. La segunda se corresponde con la década de los cincuenta; la tímida liberalización iniciada coincidió con los primeros frutos de la política de sustitución de importaciones, plasmada en un aumento de las capturas y de la producción de bacalao salado, que hizo despegar las ventas al exterior. Entre 1953 y 1960 los mercados coloniales y tropicales del continente africano absorbieron en torno al 90\%, principalmente la República del Congo (54\%), las posesiones 
francesas $(18 \%)$ y las británicas $(14 \%)$. La tercera etapa comprendería la década de los sesenta. Es sabido que el sector exterior contribuyó al éxito de las reformas económicas iniciadas en 1959 con el Plan de Estabilización y la progresiva eliminación de trabas a la actividad. En este sentido, la reforma cambiaria, la devaluación de la peseta y el nuevo sistema arancelario establecido en 1960 fueron decisivos. ${ }^{59}$ Los derechos de entrada para el bacalao se fijaron en un $15 \%$ de su valor, y, en abril de ese año, el bacalao abrió la segunda lista de mercancías incorporadas al régimen de libre importación, confirmando la política aperturista anunciada y el fin de la fase de sustitución de importaciones. ${ }^{60}$

Es conocido que una devaluación combinada con rebajas arancelarias supone una reasignación a favor de la exportación. En este sentido, el nuevo marco de comercio exterior buscaba corregir la situación deficitaria de la balanza comercial española, agravada por las importaciones de bienes de equipo y materias primas, e impulsar la exportación. Dado que muchas de las industrias importadoras también eran exportadoras potenciales, se implementaron diversos instrumentos comerciales susceptibles de estimular las ventas al extranjero. El denominado tráfico de perfeccionamiento fue el principal. Uno de sus dispositivos fundamentales, la Ley reguladora del régimen de reposición de mercancías con franquicia arancelaria, de 24 de diciembre de 1962, se relacionaba con el nuevo régimen de admisiones temporales y de devolución de derechos arancelarios. ${ }^{61}$

Desde 1962, el BOE dejó constancia de un flujo continuado de autorizaciones para la importación en régimen de admisión temporal de bacalao en verde, destinado a su transformación y exportación en seco y, en ocasiones, también de sus nuevas presentaciones: trozos, filetes, migas, etc. Pero, desde 1964, fueron casi exclusivamente de reposición con franquicia arancelaria y una duración de cinco años. Sin embargo, su importancia fue limitada. Según las ECEE, entre 1964 y 1970, el bacalao canalizado a través de admisiones temporales y reposición arancelaria no superó el 4\% de las importaciones y, entre 1971 y 1975, aún fue menor; cifras acordes con las del conjunto del comercio exterior español, que cuestionan también para la actividad bacaladera la relevancia de dichas medidas. ${ }^{62}$ Así, el dinamismo exportador quedó supeditado a la actividad de la flota bacaladera, a su rendimiento y a «la cantidad de bacalao descargado», que alcanzó su máximo en 1968, cuando se hicieron evidentes los problemas de envejecimiento de la flota, su baja productividad y el escaso aprovechamiento de su esfuerzo pesquero. ${ }^{63}$

59. Aixalá (1999); Eguidazu (1978), Viñas et al. (1979).

60. BOE, 1/04/1960; Donges (1976), p. 165; Lapuente (1985).

61. BOE, 16/03/1963.

62. Viñas et al. (1979), p. 1265; Lapuente (1981), pp. 20-23.

63. II PDES (1964), p. 86; III PDES (1972), pp. 35-36. 
Mayor importancia para las empresas tuvo la carta de exportador, un instrumento creado en 1963 dentro del Plan de Desarrollo que no se desenvolvió hasta $1966 .{ }^{64} \mathrm{Su}$ obtención les permitía acceder a diversas ayudas como créditos a la exportación para capital circulante y para la construcción de depósitos, la creación de redes comerciales o la financiación de stocks $\$$ en el extranjero; también otorgaba prioridad en la asistencia a ferias, exposiciones, misiones comerciales y otros beneficios. ${ }^{65}$ En noviembre de 1967 se aprobó un decreto de ordenación comercial de los diversos sectores para estimular las exportaciones y evitar los obstáculos de penetración exterior por una actuación fraccionada y dispersa de las empresas. Es decir, buscaba acabar con el fuerte individualismo en la actividad exportadora, fomentar el «empleo de técnicas de penetración colectiva en los mercados exteriores», y superar «la debilidad financiera y económica de un gran número de empresas exportadoras y la falta de dimensión de otras». ${ }^{66}$ En 1971, tras la constitución de un Registro Especial de Exportadores de Bacalao se otorgó la carta de primera categoría a todas las empresas exportadoras de bacalao seco y salado (partida 03.02.01). Esta categoría otorgaba nuevos beneficios: una importante desgravación fiscal a las exportaciones, mejores condiciones de acceso al crédito para capital circulante, mayores facilidades en los seguros de crédito a la exportación y cobertura de riesgos extraordinarios (políticos, comerciales o de elevación de costes). ${ }^{67}$

En definitiva, se intentaba, por un lado, dotar a unas empresas, mayoritariamente de dimensiones reducidas, de la capacidad financiera y comercial exigidas por la exportación, subvencionando los costes adicionales que requería la penetración en los mercados extranjeros; por otro, reducir los importantes riesgos del acceso a los mercados latinoamericanos o africanos, con períodos de vencimiento muy largos en las operaciones, frecuentes situaciones de insolvencia o contingencias con las divisas, y, finalmente, beneficiarse de una estrategia exportadora conjunta. ${ }^{68}$

Los datos de las exportaciones parecen reflejar los efectos positivos de estas medidas. Desde comienzo de los años sesenta la mayor orientación exportadora estuvo acompañada por una diversificación de los mercados. Entre 1960 y 1975 Portugal y Brasil fueron los principales destinos; absorbieron res-

64. BOE, 30/12/1963, 4/4/1966 y 16/11/1966. Este instrumento privilegiaba a las empresas ya existentes, al exigir para su titularidad haber alcanzado «durante los 2 ejercicios económicos precedentes a la concesión, al menos un $10 \%$ del valor de la exportación total del sector correspondiente, y representar la cifra mínima de veinte millones de pesetas al año». Para conseguir tales requisitos se permitía el agrupamiento de las empresas (BOE, 4/4/1966, pp. 39523953).

65. BOE, 9/03/1967, pp. 3262-3263 y BOE, 17/3/1967.

66. BOE, 1/12/1967; Viñas et al. (1979), p. 1281.

67. BOE, $12 / 5 / 1971$.

68. Viñas et al. (1979), pp.1281-1282 y 1339. 
GRÁFICO 12 - Exportaciones españolas de bacalao a los principales destinos (kg)

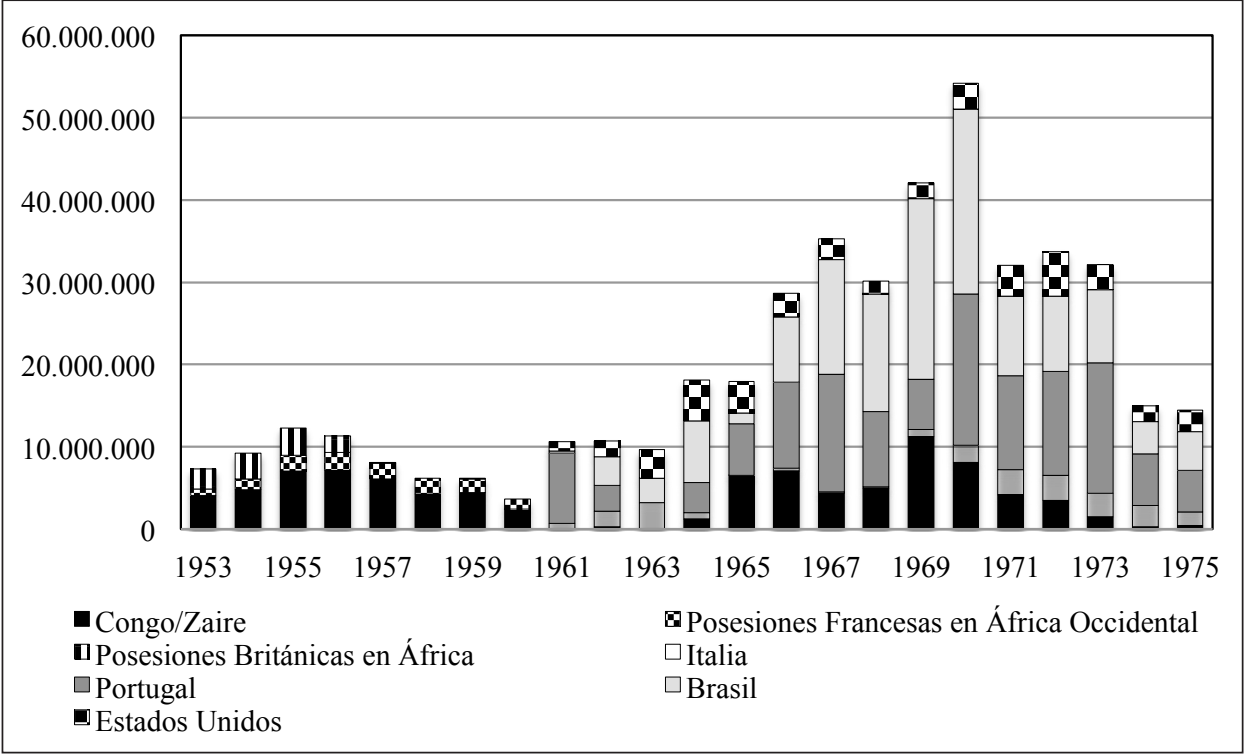

Fuente: Elaboración propia a partir de las ECEE.

pectivamente un $30 \%$ y un $26 \%$ del promedio de las ventas, superando ciertos años el 70\%. El crecimiento de las exportaciones españolas de bacalao hacia Portugal en los años sesenta se vio favorecido desde el lado portugués por la política aperturista del comercio de bacalao promovida por el Gobierno, que culminó en 1967 con su liberalización definitiva, y, desde el lado español, por el dinamismo de los agentes exportadores y la influencia favorable de los tipos de cambios entre la peseta y el escudo, tras las devaluaciones de la primera de los años 1957, 1959 y $1967 .{ }^{69}$ El bacalao español inundó el mercado portugués, alcanzando casi el 70\% de las importaciones individuales en la campaña de 1966-1967..$^{70}$ También el bacalao español volvió al mercado del Congo, que mantuvo un peso significativo en el conjunto (13\%), similar al de Estados Unidos $(12 \%)$ y superior al de Italia $(8 \%)$. Estos cinco países absorbieron entre 1960 y 1975 más del $90 \%$ del total de las exportaciones de bacalao. ${ }^{71}$

El aumento de las exportaciones de bacalao no sólo permitió compensar unas importaciones cuyo valor se incrementó progresivamente sino también cambiar el signo de la balanza comercial en la década de 1960, obteniendo

69. Una peseta equivalía a 1,28 escudos en 1957 , a 0,48 en 1960 y a 0,41 en 1968 (Banco de Portugal, 2018).

70. Garrido, A. (2004), pp. 398-420.

71. IRESCO (1977). 
GRÁFICO 13 - Balanza comercial del bacalao (miles de pesetas corrientes)

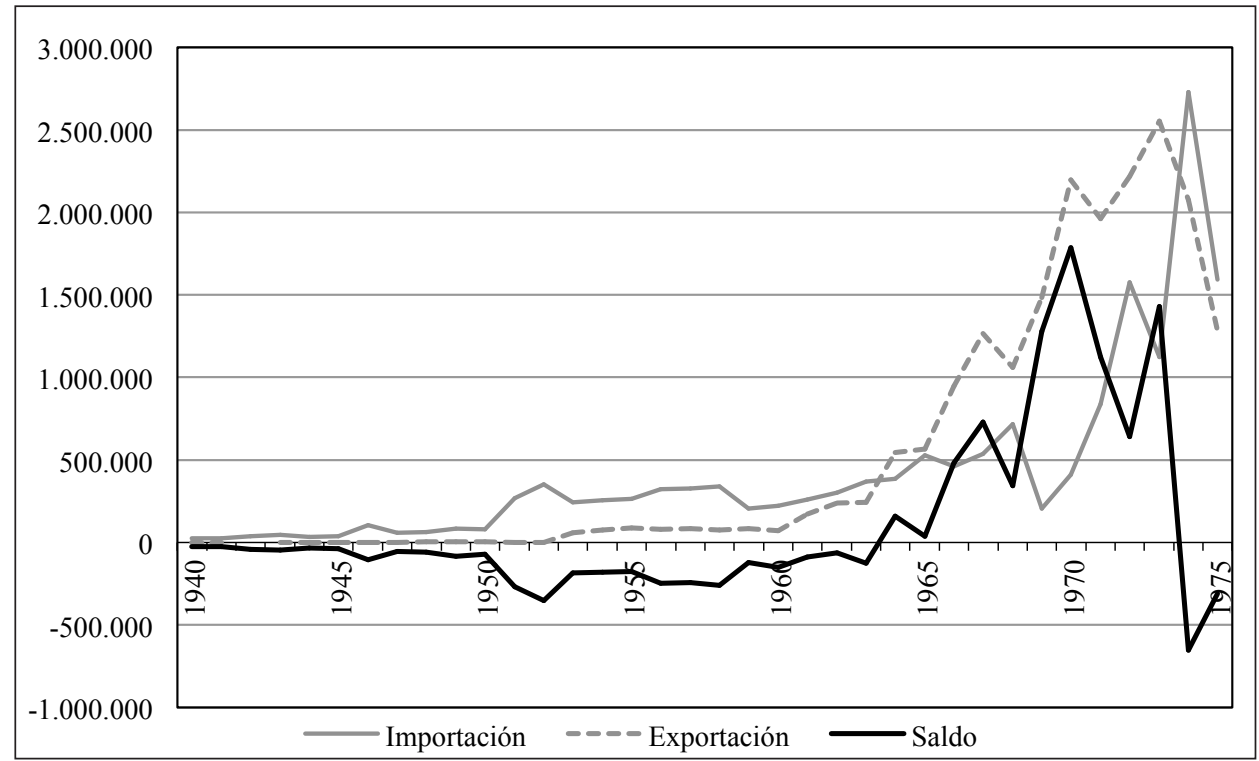

Fuente: Elaboración propia a partir de las ECEE.

por primera vez un superávit. Desde 1964 el saldo fue positivo y en 1970 se logró el mayor excedente, con 2.198 millones de pesetas. A partir de 1974, con la actividad pesquera en claro retroceso y un contexto fuertemente inflacionista que elevaba los costes, la balanza volvió a ser negativa. ${ }^{72}$

Ahora bien, en estos años los mercados internacionales de bacalao se vieron progresivamente saturados, pues la caída de los precios del pescado congelado animó a ciertos productores, caso de Noruega, a reorientarse hacia la salazón de bacalao. El derrumbe de las cotizaciones afectó a los resultados de las «empresas nacionales», que año tras año veían incrementarse sus dificultades para competir en los mercados, tanto nacional como extranjeros. ${ }^{73}$

El excedente comercial conseguido representaba un éxito evidente de la «nacionalización» de la actividad bacaladera, pero también en parte el retroceso en el consumo de bacalao en España. Se abría una etapa en la cual el crecimiento de la producción y la industrialización del bacalao alimentaban la

72. El crecimiento de las importaciones a lo largo de los años sesenta, no tanto en volumen como en valor, seguramente pueda relacionarse con una importación de bacalao centrada en las calidades superiores, tradicionalmente más apreciadas en los mercados mediterráneos, mientras las inferiores, mayoritarias en las capturas de la flota española, nutrían las exportaciones hacia mercados menos exigentes como el Congo o Brasil (Garrido, 2004:417; Ritcher, 2015; PEBSA, Libro II de Actas de la Junta General de Accionistas, 31/12/1968).

73. PEBSA, Libro II de Actas de la Junta General de Accionistas; Garrido (2004), pp. 415-416. 
demanda de exportación. Así, las proyecciones realizadas por el primer Plan de Desarrollo Económico y Social para el período 1961-1967 apuntaban una reducción de las importaciones de salazones y del consumo nacional de un $14 \%$ y un $10 \%$ respectivamente, al tiempo que preveían un aumento de las exportaciones del 124\%. ${ }^{74}$ En 1967 el II Plan de Desarrollo reiteró:

... el elevado porcentaje que las exportaciones representan respecto a la producción nacional (más de un 53\%) y su favorable trayectoria, junto con el carácter de bien de consumo regresivo que este producto viene representando en nuestro país, nos hace pensar que en un futuro próximo esta actividad será fundamentalmente exportadora, con más de un $70 \%$ de su producción. ${ }^{75}$

En los años centrales de la década, las salazones se situaron por delante de las conservas de pescado, que hasta entonces habían ocupado el primer puesto en las ventas de productos marinos, pero por detrás del pescado fresco, congelado y refrigerado. Las salazones tenían un potencial exportador con gran capacidad para generar divisas.

El optimismo en los mercados exteriores contrastaba con los cambios en el mercado interior y que afectaban tanto a los formatos como al tipo de bacalao consumido. En lo que se refiere al primero, y como indicó en 1967 el II PDES:

... en España está evolucionando el mercado del bacalao, tendiendo cada vez más a una adecuada presentación en bolsas o paquetes de pequeñas raciones susceptibles de ser compradas para las necesidades del día en el hogar. En este sentido, la preparación de filetes, trozos, bacalao desmigado, va siendo cada vez más necesaria, porque a la larga estamos abocados a la desaparición de la bacalada clásica que se veía en las tiendas de los comerciantes detallistas. ${ }^{76}$

En 1970, las presentaciones preenvasadas representaron alrededor del 25\% del consumo español; asociándose a las transformaciones de la distribución alimentaria al por menor y de los hábitos de consumo vinculados a los autoservicios, cuya lenta difusión en la década de los sesenta se aceleró en los se-

74. PDES (1963), p. 264. El bacalao salado y seco era la especie principal de las salazones, representando más del $62 \%$ del total, seguida por la anchoa con el $20 \%$ (II PDES, 1967:85).

75. II PDES (1967), pp. 105-108.

76. II PDES (1967), p. 88. En esos años estaban llegando las primeras partidas de bacalao congelado y transformado, tal como hizo constar en 1967 la Dirección General de Aduanas, al aclarar que la partida 03.01C. 1164 «Filetes de pescado, congelados y rebozados» incluía filetes, generalmente de bacalao fresco y róbalo (Ministerio de Hacienda, 1967). Algo más tarde, en 1972, las ECEE desglosaron una nueva partida, «Los demás bacalaos» (PA 03.02.09) (ECEE, 1972). 
tenta. ${ }^{77}$ El segundo cambio estuvo relacionado con el tipo de curado exigido, al «apetecer cada vez más el bacalao con un alto grado de humedad, porque es más apto para el consumo», algo propiciado por la expansión de los sistemas de frío a lo largo de la cadena comercial y del rápido crecimiento del número de frigoríficos domésticos. ${ }^{78}$ Ambos procesos se afianzaron desde mediados de los años setenta.

Y, si el consumo de la tradicional hoja de bacalao flaqueaba en favor de nuevos formatos y clases, también se retraía la demanda del propio producto salado y seco. El bacalao se mostraba como un producto tradicional muy maduro, cuyo ciclo de vida se adentraba en una fase de rápido declive. De hecho, se consideraba un artículo en regresión, afectado por el aumento del nivel de vida y la oferta de otros productos, en forma de un consumo «decreciente, como corresponde a su carácter de bien inferior». ${ }^{79}$ En 1964-1965, el INE estimaba un consumo por habitante y año de $1 \mathrm{~kg}$, cifra inferior a la calculada por nosotros (tabla 5), oscilando entre los $1,2 \mathrm{~kg}$ en el ámbito rural y los $0,9 \mathrm{~kg}$ del urbano ${ }^{80} \mathrm{La}$ tendencia se confirmó a comienzos de los setenta, al situarse su consumo per cápita en menos de la mitad del de una década antes. Por el contrario, las exportaciones de bacalao fueron crecientes: representaron el $27 \%$ de la producción en $1960-1964$, el $64 \%$ en $1965-69$ y el $90 \%$ en 1970-1974. Las empresas transformadoras, conscientes del progresivo debilitamiento de la demanda interna, apostaron por un impulso a la exportación a largo plazo, sometiéndose a los costes de la internacionalización, animadas por los diferentes mecanismos de fomento que la política económica tardofranquista ponía a su disposición. ${ }^{81}$

TABLA 5 - Consumo aparente de bacalao en salazón en España (kg/persona)

\begin{tabular}{llll}
\hline $1940-1944$ & 0,50 & $1960-64$ & 1,51 \\
\hline $1945-1949$ & 1,00 & $1965-69$ & 0,97 \\
\hline $1950-1954$ & 1,43 & $1970-74$ & 0,71 \\
\hline $1955-1959$ & 1,09 & & \\
\hline
\end{tabular}

Fuente: Elaboración propia a partir de las ECEE, Barbancho (1960) e Industrias derivadas de la pesca.

77. Lummel (2007); García Ruiz (2007); Richter (2015), Maixé (2009).

78. II PDES (1967), p. 88.

79. II PDES (1967), pp. 44-45; (1970), p. 78.

80. INE (1969). El declive del bacalao salado en estos años también ha sido constatado por aquellos autores que se han ocupado del consumo de pescado en España: Piquero y López (2005).

81. Viñas et al. (1979), p.1326. 
En todo caso, desde hacía tiempo era evidente la contracción que estaban experimentando los mercados mundiales del bacalao salado y seco. Esta contracción generó cambios de gran alcance, al animar a Islandia, Terranova o Noruega a reorientar sus producciones hacia el congelado. En los años cincuenta y sesenta el desarrollo de nuevas pautas de consumo y las modernas formas de distribución y comercialización provocaron un rápido aumento de la demanda de pescado congelado procesado en forma de bloques, filetes, fish sticks o hamburguesas. Los amplios mercados de estos nuevos productos estimularon la rápida difusión de la tecnología de la congelación en los principales países productores de bacalao salado, primero en Estados Unidos, después en Gran Bretaña o Alemania Federal, y, más tarde, en países como España o Portugal. ${ }^{82}$ Esto hizo que ciertas voces autorizadas constataran la cada vez menor importancia del mercado de bacalao salado, pronosticando su próxima desaparición por la diminution de la demande de produits fortement salés et séchés dans le pays developpés, pero sin olvidar la potencialidad existente en ciertos mercados latinoamericanos y africanos. ${ }^{83}$ Una visión muy próxima a la de los planes de desarrollo que, ante las desfavorables perspectivas para el consumo de bacalao en los mercados tradicionales, apuntaban hacia las exclusivas posibilidades de expansión «en aquellos países de bajo nivel de vida y en vías de desarrollo». De hecho, fue en estos mercados donde las producciones españolas se introdujeron en los años sesenta con más intensidad, logrando desplazar a las de otros países. ${ }^{84}$

Esta vocación exportadora comenzó a ponerse en cuestión a finales de la década. La primera señal de alarma se dio en 1968 al plantearse un problema de acumulación de excedentes. El aumento de la producción bacaladera en los años precedentes acabó revelando no sólo la inelasticidad del consumo nacional, «bastante estratificado por comarcas y aún por estaciones del año», sino una contracción del mercado interior «mayor cada día». ${ }^{85}$ El exceso de oferta tropezó con la incapacidad del mercado interior para absorberla. Los grupos productores achacaron la saturación del mercado al repunte de las importaciones, excitadas ese año por la bonificación arancelaria del 100\%, implantada en diciembre de 1967, cuando las capturas de la flota alcanzaban su máximo. Y a los excedentes de bacalao se les sumó una acumulación de stocks de pescado congelado, fruto del rápido crecimiento de su producción desde comienzos de los años sesenta, evidenciando que las dos ramas de la pesca de gran altura, bacaladera y congeladora, estaban compitiendo entre sí, en los mer-

82. Jónsson \& Jónsson (2013); Jónsson (2009); Finstad (2004), (2013); Josephson (2008); Hamilton (2003); Wright (1997).

83. OCDE (1968), p. 6.

84. PDES (1964), pp. 88,105; (1970), p. 61.

85. IP, $1 / 12 / 1967 ; 15 / 05 / 1968$. 
cados del interior y en los exteriores. ${ }^{86}$ A esto tampoco debieron ser ajenos los cambios que se estaban produciendo en la industria alimentaria y en la dieta española, con una mayor disponibilidad de carnes, huevos, etc. ${ }^{87}$

La salida encontrada fue la protección de la producción nacional y el impulso de las exportaciones. La supresión de la bonificación arancelaria tuvo un efecto inmediato; en 1969 las importaciones se derrumbaron, permaneciendo muy bajas en los dos años siguientes, mientras las exportaciones se dispararon, ayudadas por la devaluación de la peseta de 1967, las medidas estabilizadoras y de fomento comercial. Crecieron las ventas hacia Estados Unidos, Italia o Zambia, y sobre todo a Brasil y Portugal, un mercado en esos años «atestado de bacalao español». ${ }^{88} \mathrm{Al}$ mismo tiempo, se insistió en la estandarización y en la calidad de los productos, conforme a las exigencias de una demanda orientada a la exportación. La preocupación por la calidad mostrada en los planes de desarrollo y la promulgación en 1967 del primer Código Alimentario Español se acabaron plasmando en diversas normas de calidad decretadas para el bacalao exportado y adaptadas a los mercados exteriores. ${ }^{89}$

Ahora bien, la intensificación de las ventas exteriores se hizo básicamente a costa de los precios del bacalao. Así PEBSA, enfrentada tanto a la competencia de otros países europeos como de los nuevos secaderos españoles, reconoció que: «... para recuperar los mercados extranjeros nos hemos visto obligados a reducir sensiblemente los precios, con el fin de no perder los mismos».$^{90}$ Aun así, el crecimiento de la producción basado en los mercados exteriores duró poco. A comienzos de 1970 el Ministerio de Comercio, aconsejado por el alza de precios en el mercado interior y el nivel de precios exteriores, acordó suprimir por tres meses los derechos arancelarios al bacalao, lo que no evitó que en diciembre tuviera que subvencionar el bacalao nacional, habilitando un crédito de setenta y cinco millones de pesetas. ${ }^{91} \mathrm{Al}$ año siguiente las exportaciones se contrajeron, anunciando su caída imparable. El continuado descenso de las capturas fue restando competitividad a las producciones españolas, incrementándose los diferenciales de precios entre importaciones y exportaciones (gráfico 14). Desde 1971 el superávit de la balanza comercial de este producto se debilitó, entrando dos años más tarde en valores negativos. Sin el empuje de la producción, cuyas capturas en 1973 ape-

86. IP, 1/12/1967; Giráldez (2008).

87. Constituyen un buen ejemplo de este proceso, el desarrollo de la producción intensiva de carne (porcino, aves o conejo) o el del pescado congelado (Segrelles Serrano, 1990, capítulo 8; Giráldez, 2008; Cussó y Garrabou, 2009; Clar, 2009).

88. Garrido (2004), p. 417.

89. PDES (1967), pp. 86-89; BOE, 17/10/1968; 24/12/1968; 15/5/1969; 25/1/1971.

90. PEBSA, Libro II de Actas de la Junta General de Accionistas, 25/7/1969.

91. BOE, $17 / 2 / 1970 ; 5 / 12 / 1970$. 
GRÁFICO 14 - Precio de las importaciones y exportaciones de bacalao (miles de pesetas/Tm)

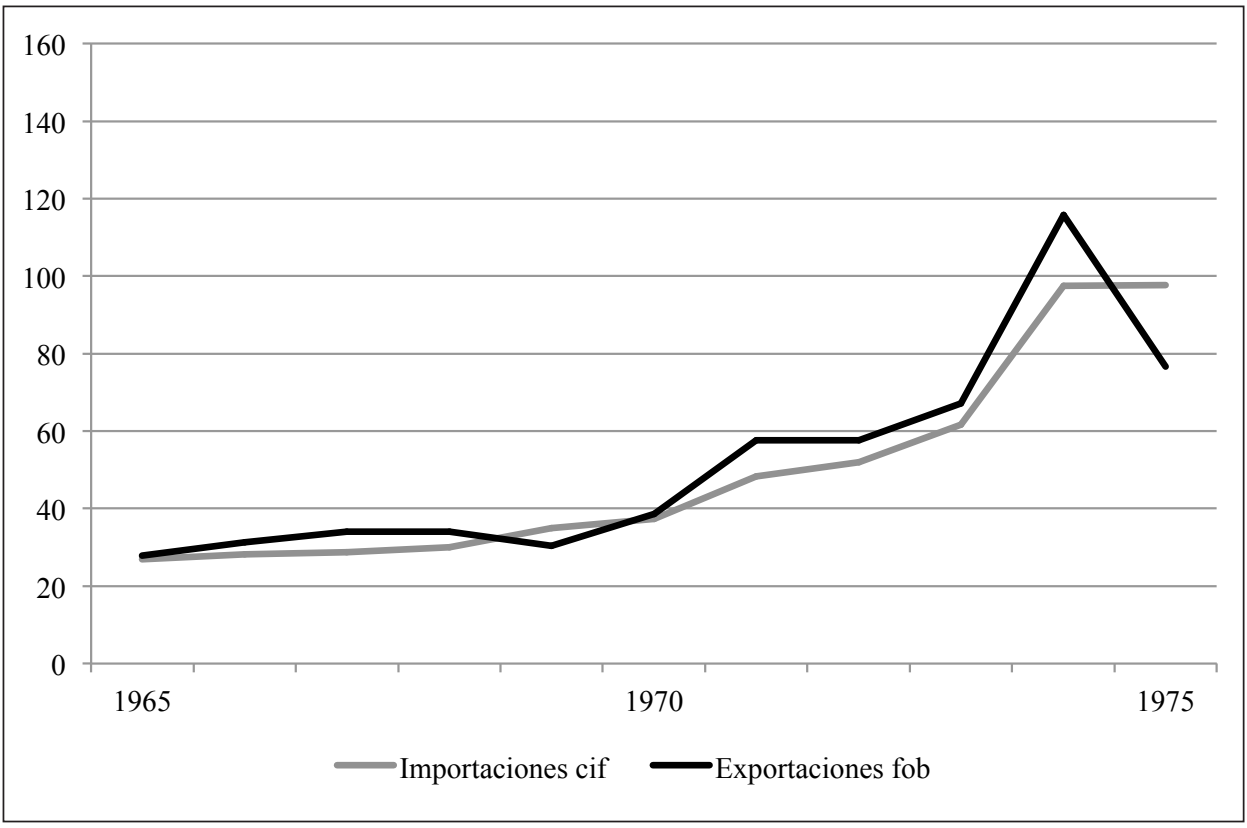

Fuente: Elaboración propia a partir de las ECEE.

nas fueron la mitad de las de cuatro años antes, y con una peseta que dificultó la competitividad, pues se apreció en términos reales entre 1970-74, la fase de industrialización del bacalao orientada hacia la exportación finalizó abruptamente.

\section{Conclusiones}

El franquismo abrió una nueva etapa del papel del bacalao en la economía española. Bajo la influencia de una coyuntura desfavorable en los intercambios exteriores, España abandonó el mercado internacional de bacalao. Al mismo tiempo, la confianza en la autarquía económica y la política de condicionamiento industrial del primer franquismo impulsaron la actuación del capital privado, con grandes ayudas e inversiones a la pesca e industrialización de la actividad bacaladera. El Crédito Naval asentó un mecanismo privilegiado de desarrollo de la flota, aunque el inicio de la Segunda Guerra Mundial y las graves carencias de la economía española ralentizaron el proceso de sustitución de importaciones, que sólo adquirió intensidad desde comienzos de la década de los cincuenta. 
En sus inicios, la farragosa y arbitraria regulación de la política industrial y pesquera del franquismo dio lugar a un monopolio de la actividad bacaladera, que quedó restringida a las denominadas empresas bacaladeras nacionales. Sin embargo, en los años cincuenta, al ser una rama productora de alimentos y dada la situación generalizada de escasez, también se abrió a las casas armadoras tradicionales, antes dedicadas a la pesca de altura en fresco. Esta apertura estimuló el crecimiento de las capturas y de la producción de bacalao salado y seco, aunque en la práctica su procesado siguiera manteniéndose en las «empresas nacionales».

La liberalización de la economía española y la remodelación del crédito naval dieron un nuevo impulso a la actividad bacaladera en los años sesenta. El crecimiento y la modernización de la flota provocaron un continuado aumento de las descargas, permitiendo que el consumo per cápita de bacalao alcanzara su máximo en la primera mitad de la década; después cayó de forma continuada, evidenciando que el tradicional bacalao seco y salado era ya un producto muy maduro, que remitía a una matriz tecnológica anticuada. El bacalao se mostraba como un anacronismo, una «bizarría cultural», como indicó Garrido para el caso de Portugal. ${ }^{92}$ La sustitución de importaciones llegaba a su fin mientras crecían las exportaciones, impulsadas por el aumento de la producción y fomentadas por el Estado. La industria transformadora se orientó cada vez más hacia la exportación y consolidó su crecimiento, tanto en número de establecimientos como en volumen de producción. La nueva orientación ratificó su éxito con un significativo saldo positivo de la balanza comercial, confirmando que la actividad bacaladera constituía un importante capítulo en la obtención de divisas. Sin embargo, el crecimiento de la actividad, asentado en unas capturas crecientes efectuadas por una flota en aguas libres, comenzó a cuestionarse a comienzos de los años setenta con el agotamiento del recurso. La continuada y rápida caída de la producción pesquera arrastró consigo a la flota, a la transformación y a las exportaciones, a las que tampoco ayudó la apreciación de la peseta en los primeros setenta; la balanza comercial se deterioró, incrementando su saldo negativo. Concluía la ansiada «nacionalización» de la pesca del bacalao. En 1977, Canadá extendió unilateralmente su zona de pesca exclusiva hasta las $200 \mathrm{mi}-$ llas, a fin de paliar la situación de sobrepesca. Esta medida acentuó la agonía para una flota bacaladera en acelerado declive. España volvió a convertirse en un destacado importador. Se cerraba el ciclo español del bacalao. 


\section{BIBLIOGRAFÍA}

Aixalá Pastó, J. (1999). La peseta y los precios. Un análisis de largo plazo (1868-1995). Zaragoza: Prensas Universitarias de Zaragoza.

Alemany, F. (1973). «Estructura de la flota bacaladera». Información Comercial Española, n. ${ }^{\circ} 478$, pp. $129-141$.

Alonso Herrera, J. (1982). Los medios jurídicos y económicos de la política marítima en España. Madrid: Fareso.

Banco de Portugal (Bpstat). Estadísticas. Disponible en línea: https://www.bportugal. pt/EstatisticasWeb/(S(bykpru55jyyb5y55acu5pf55))/SeriesCronologicas.aspx [consultada 15/01/2018].

BArbancho, A. G. (1960). «Análisis de la alimentación española (conclusión)». Anales de Economía, vol. 18, n. ${ }^{\circ}$ 67, pp. 271-355.

BARCiela LóPez, C. (1989). «Sector agrario (desde 1936)». En: CARRERAS I Odriozola, A. (coord.), Estadísticas Históricas de España. Madrid: Fundación Banco Exterior, pp.131-168.

Barkham, M.; López Losa, E. (1999). «Pasajes puerto pesquero». En: Pasaia. Memoria histórica y perspectivas de futuro. Donostia: Museo Naval, Diputación Foral de Gipuzkoa, pp. 75-147.

BuesA, M.; PIRES, L. E. (2002). «Intervencionismo estatal durante el franquismo tardío: la regulación de la inversión industrial en España (1963-1980)». Revista de Historia Industrial, n. ${ }^{\circ}$ 21, pp. 159-198.

Carmona Badía, X.; Alonso Álvarez, L. (2006). «La configuración del tejido empresarial de Galicia (1880-2002)». En: García Ruiz, J. L.; Manera Erbina, C., Historia empresarial de España. Un enfoque regional en profundidad. Madrid: LID, pp. 281-314.

Carmona Badía, X.; Nadal Oller, J. (2005). El empeño industrial de Galicia. 250 años de historia, 1750-2000. A Coruña: Fundación Barrié de la Maza.

Clar Moliner, E. (2009). «La soberanía del productor. Industrias del complejo piensoganadero e implantación del modelo de consumo fordista en España». En: GERMÁN Zubero, L.; Hernández García, R.; Moreno LÁzaro, J., Economía alimentaria en España durante el siglo XX. Madrid: Ministerio de Medio Ambiente y Medio Rural y Marino, pp. 99-143.

Comisaría del Plan de Desarrollo Económico y Social. Plan de Desarrollo Económico y Social años 1964-1975. Madrid: BOE, Presidencia del Gobierno.

Comisión de Pesca Marítima (1967). II Plan de Desarrollo Económico y Social, Pesca Marítima. Madrid: BOE, Presidencia del Gobierno.

Comisión de Pesca (1972). III Plan de Desarrollo Económico y Social, Pesca Marítima 1972-1975. Madrid: BOE, Presidencia del Gobierno.

CopiBA. Memoria del ejercicio (1940, 1949, 1950, 1951, 1958).

Cussó i Segura, X.; Garrabou Segura, R. (2009). «Dieta mediterránea y transición nutricional en España». En: Germán Zubero, L.; Hernández García, R.; More- 
NO LÁZARo, J., Economía alimentaria en España durante el siglo XX. Madrid: Ministerio de Medio Ambiente y Medio Rural y Marino, pp. 25-65.

Dirección General de Pesca Marítima. Estadística de Pesca. Madrid. 1940-1972.

Dirección General de Pesca Marítima. Anuario de Pesca Marítima. Madrid. 19731975.

Donges, J. B. (1976). La industrialización en España. Políticas, logros, perspectivas. Barcelona: Oikos-Tau.

EGUIDAZU, F. (1978). Intervención monetaria y control de cambios en España, 1900-1977. Madrid: ICE/Libros.

EiroA Del Río, F. (1997). Historia y desarrollo de la pesca de arrastre en Galicia: siglos $X V I I$ al XX. A Coruña: Diputación Provincial de A Coruña.

- (2002). A pesca profesional e a súa técnica. Santiago de Compostela: Xunta de Galicia.

Escudero Domínguez, L. J.; LóPez LosA, E. (2011). «Los Serrats. El triunfo del esfuerzo». En: CARMONA BADÍA, X. (coord.), Las familias de la conserva. El sector de las conservas de pescados a través de sus sagas familiares. Vigo: Diputación de Pontevedra, Fundación Clúster de Conservación de Productos del Mar, Anfaco-Cecopesca, pp. 220-245.

Espido Bello, M. C.; GirÁldez Rivero, J. (2015). «El bacalao en España (1850-1914): importación y política comercial». Historia Agraria, n. ${ }^{\circ}$ 67, pp. 41-73.

FAO. Yearbook of fishery statistics. Catches and Landings. Roma. 1972-1977.

Finstad, B. P. (2004). «The Frozen Fillet: The Fish that Changed North Norway?». International Journal of Maritime History, vol. 16, n. ${ }^{\circ}$ 1, pp. 27-41.

Fuentes IruRozQui, M. (1962). El comercio exterior de España (1940-1960). Madrid: Arbor.

Garay Unibaso, F. (1985). «La pequeña historia de nuestros pescadores de bacalao». El Campo, n. ${ }^{\circ} 99$, pp. 8-20.

GARCíA Ruiz, J. L. (2007). «Cultural Resistance and the Gradual Emergence of Modern Marketing and Retailing Practices in Spain, 1950-1975». Business History, vol. 49, n. ${ }^{\circ}$ 3, pp. 367-384.

García-Orellán, R.; Beobide Arburúa, J. (2004). Hombres de Terranova. La pesca del bacalao, 1926-2004. Pasajes: Autoridad Portuaria de Pasajes.

Garrido, Á. (2004). O Estado Novo e a Campanha do Bacalhau. Rio de Mouro: Círculo Leitores.

Gerhardsen, G. M.; Gertenbach, L. P. D. (1949). Bacalao y especies afines saladas. Washington: FAO.

GirÁldez Rivero, J. (2005). «El bulto y la sombra: la financiación del sector pesquero y la hipoteca naval». Comunicación presentada en el VIII Congreso de la Asociación Española de Historia Económica, Santiago de Compostela.

- (2008). «Revisitando el nudo gordiano: el desarrollo de la congelación en la pesca gallega (1960-1970)». Áreas, n. ${ }^{\circ} 27$, pp. 69-79. 
GonzÁlez LaXe, F. (1983). El proceso de crecimiento del sector pesquero español (19611979). A Coruña: Caja de Ahorros de Galicia.

Hamilton, S. (2003). «The economies and conveniences of modern-day living: Frozen foods and mass marketing, 1945-1965». Business History Review, n. ${ }^{\circ}$ 77, pp. 33-60.

Houpt, S.; Ortiz-Villajos, J. M. (dirs.) (1998). Astilleros Españoles 1872- 1998. La construcción naval en España. Madrid: LID.

Instituto NACiONAL de Estadística (1969). Encuesta de presupuestos familiares (marzo 1964-marzo 1965). Madrid.

Instituto Nacional de Estadística. Industrias derivadas de la pesca, Madrid, 1953-1975.

Instituto de Reforma de las Estructura Comerciales (IRESCO) (1977). Comercialización de la pesca. Madrid: Ministerio de Comercio.

JónSSON, G. (2009). «Fishing nations in crisis: The responses of the Icelandic and Norwegian fisheries to the great Depression». International Journal of maritime History, vol. $21,{ }^{\circ}{ }^{\circ}$, pp. $127-151$.

JónSSON, G.; JónsSON Ö. D. (2013). «The rise of the frozen-fish industry in Iceland and Norway: The case of the fish fingers». En: OdDY, D. J.; DrouARD, A. (eds.), The food industries of Europe in the nineteenth and twentieth centuries. Surrey: Ashgate, pp. 147161.

Josephson, P. (2008). «The ocean hot dog. The development of the fish stick». Tecnology and Culture, vol. 49, n. $^{\circ} 1$, pp. 41-61.

Landeta Bilbao, J. (1996). Aportación al estudio de la pesca del bacalao en el área del Atlántico Norte [tesis doctoral]. Cádiz: Universidad de Cádiz.

LAPuente Moreno, F. (1981). El tráfico de perfeccionamiento activo en España. Barcelona: Cámara Oficial de Comercio, Industria y Navegación de Barcelona.

- (1985): Introducción al arancel español. Barcelona: Cámara Oficial de Comercio, Industria y Navegación de Barcelona.

Lledó Martín, J. (1943). La pesca nacional. Madrid: Pegaso.

LÓPEZ LosA, E. (2001). «El sector pesquero y la industria transformadora de pescado en el País Vasco (1880-1936). Una historia económica» [tesis doctoral]. Universidad del País Vasco, Departamento de Historia e Instituciones Económicas.

- (2001). «Spanish Atlantic Cod (Gadus Morhua) in Newfoundland in the second half of the 20th century». En Zeller, D.; Watson, R.; PAuly, D. (eds.) (2001). Fisheries impacts on North Atlantic ecosystems: Catch, effort and nationallregional data sets. Fisheries Centre Research Reports, vol. 9, n. ${ }^{\circ}$ 3, pp. 231-235.

- (2008). «La pesca en el País Vasco durante el siglo Xx. Modernización, tradición y crisis». ÁREAS, n. ${ }^{\circ}$ 27, pp. 7-25.

Lummel, P. (2007). «Born-in-the-city: The supermarket in Germany». En: AtKins, P. J.; Lummel, P.; OdDy, D. J. (eds.) (2007). Food and the city in Europe since 1800. Hampshire: Ashgate, pp. 165-175.

MAiXÉ-Altés, J. C. (2009). «La modernización de la distribución alimentaria en España, 1947-1997». Revista de Historia Industrial, n. ${ }^{\circ}$ 41, pp. 125-160. 
Ministerio DE HACIENDA (1967). Índice de criterios de clasificación arancelaria (2 vols.). Madrid: Servicio de Publicaciones de la Dirección General de Aduanas.

OCDE (1968). Marché du poisson congelé dans les pays membres de l'OCDE 1964-1968. París: OCDE.

Ogea Porta, P.; Balseyro, F. (1944). La Marina y el crédito naval. Estudio económico, histórico y de legislación financiera. Madrid: Morata.

OYA, J. J. (1976). «Las pesquerías españolas en onda larga: la «gran pesca» del bacalao en los bancos del Atlántico noroccidental». Revista de Geografía, vol. 10, n. ${ }^{\circ} 1-2$, pp. 48 78 .

PAZ AndRAde, V. (1967). «La problemática económica de las pesquerías de onda larga». Información Comercial Española, n. ${ }^{\circ} 411$, pp. 81-89.

- (1973). «El proceso de expansión de las pesquerías españolas». Información Comercial Española, n. ${ }^{\circ} 478$, pp. 83-91.

PeBsa. Libro de Actas de la Junta General II (1956-1993).

PEBSA. Memoria correspondiente al ejercicio de... (1942-1977).

PÉrez FARiÑA, M. L. (1985). «La industria del bacalao en Galicia: la importancia de la Ría de Arosa». Paralelo, vol. 37, n. ${ }^{\circ} 8-9$, pp. 429-444.

Piquero Zarauz, S.; López Losa, E. (2005). «El consumo de pescado en España. Siglos XVIII-XX: una primera aproximación». XI Congreso de Historia Agraria, Sesión III, Economía alimentaria de la era agrícola a la industrial, Aguilar de Campoo.

Pires Jiménez, L. E. (2003). Regulación industrial y atraso económico en la dictadura de Franco. Madrid: Dykinson.

- (2005). «Los empresarios y el Estado en torno a las intervenciones del régimen de Franco: la regulación de la inversión industrial (1938-1963)». Investigaciones de Historia Económica, vol. 1, n. ${ }^{\circ}$ 2, pp. 145-178.

Richter-HANSEN, E. (2015). «The history of the Norwegian-Spanish salted fish trade». En: Lindk vist, K. B.; Trondsen, T. (eds.), Nordic-Iberain Cod Value Chains. Explaining salted fish trade patterns, Ámsterdam: Mare-Springer, pp. 23-41.

Rodríguez Martín, O. (1965). «Comentarios en torno a las pesquerías del Atlántico Noroeste (ICNAF)». Publicaciones Técnicas de la Junta de Estudios de Pesca (Subsecretaría de la Marina Mercante), n. ${ }^{\circ}$ 4, pp. 331-349.

- (1967). «La participación española en aguas de Terranova, Groenlandia y Labrador». Información Comercial Española, n. ${ }^{\circ}$ 411, pp. 101-107.

Santacreu Soler, J. M. (1988). Cambio económico y conflicto bélico. Transformaciones económicas en la retaguardia republicana. Alicante 1936-1939 [tesis doctoral]. Universidad de Alicante.

Segrelles Serrano, J. A. (1990). La ganadería industrial en España: cabaña porcina y avicultura de carne [tesis doctoral]. Universidad de Alicante.

Servicio sindical de estadística (1969). Catálogo de empresas del Sindicato de la Pesca (2 vols.). Madrid: Ediciones y Publicaciones Populares. 
Sinde Cantorna, A. (2000). Estrategias de crecimiento y formas de integración en la empresa pesquera gallega. Madrid: Documentos de Trabajo Fundación Empresa Pública.

Sinde Cantorna, A.; Fernández Vázquez, M. T.; Diéguez Castrillón, I. (2002). «El proceso de difusión tecnológica en la pesca de altura del norte de España». Historia Agraria, n. ${ }^{\circ}$ 28, pp. 113-136.

Tolosa Bernárdez, M. T. (1984). «La crisis pesquera del puerto de Pasajes». Lurralde, n. ${ }^{\circ}$ 7, pp. 267-285.

- (2000). «La pesca del bacalao en el siglo XX: el caso de la Compañía PYSBE». Itsas Memoria. Revista de Estudios Marítimos del País Vasco, n. ${ }^{\circ}$ 3, pp. 363-382.

Torres Villanueva, E. (2006). «La empresa en el País Vasco (siglos XIX y XX)». En: GarCía Ruiz, J. L.; Manera Erbina, C. (dirs.), Historia empresarial de España. Un enfoque regional en profundidad. Madrid: LID, pp. 211-239.

Urrutia OchOA, P. (2003). «El Gran Banco de Terranova: mareas, mitos y miserias». Itsas Memoria. Revista de Estudios Marítimos del País Vasco, n. ${ }^{\circ}$ 4, pp. 595-618.

Viñas, Á.; Viñuela, J.; Eguidazu, F.; Fernández Pulgar, C.; Florensa, S. (1979). Política comercial exterior en España (1931-1975) (3 vols.). Madrid: Banco Exterior de España.

Wright, M. (1997). «Frozen fish companies. The state and the fisheries development in Newfoundland, 1940-1966». Business and Economic History, vol. 26, n. ${ }^{\circ}$ 2, pp. $727-$ 736. 


\title{
The cod industry under the Franco regime (1939-1975)
}

\begin{abstract}
This paper studies the history of salt and dried Atlantic cod production in Spain throughout the Franco regime. Cod was a product traditionally imported into Spain, but during this period the country became one of the main producers. We first examine the cod fishing activity and the strong economic incentives deployed to promote it, the problems of setting up a specific fleet, the growth of landings and the start-up of a processing industry; then we analyze the stage of its maturity, changes in the cod fishing fleet, and the evolution of catches. Next we look at the processing industry, its production, location, size and developments. Finally, we study the Spanish foreign trade in cod and conditioning factors, with special attention given to economic policy related to the cod industry - a sector that went from producing cheap food for domestic consumption to targeting demand from outside markets.
\end{abstract}

KEY WORDS: Atlantic cod, fisheries, food, Franco regime, foreign trade

JEL CODES: N54, N64, N74, Q21

\section{La actividad bacaladera bajo el franquismo (1939-1975)}

\section{RESUMEN}

Este trabajo estudia la trayectoria de la producción de bacalao del Atlántico salado y seco, un producto tradicionalmente importado en España y del cual, durante el régimen franquista, el país se convirtió en uno de los principales productores. Comenzamos examinando la actividad extractiva y los fuertes estímulos económicos desplegados para su fomento, los problemas para la constitución de una flota específica, el crecimiento de las descargas y el arranque de una industria de procesado; después analizamos su etapa de madurez, los cambios en la flota y la evolución de las capturas. A continuación examinamos la industria transformadora, su producción, localización, dimensión y cambios. Finalmente estudiamos el comercio exterior español de bacalao y sus condicionantes, prestando atención a la política económica en torno a la cual giró la actividad bacaladera; una rama que pasó de estar destinada a proporcionar alimentos baratos al mercado interior a orientarse hacia la demanda procedente de los mercados exteriores.

PALABRAS ClAVE: bacalao del Atlántico, pesquerías, alimentación, comercio exterior, franquismo

Códigos JEL: N54, N64, N74, Q21 